\title{
Effect of passaging on the stemness of infrapatellar fat pad-derived stem cells and potential role of nucleostemin as a prognostic marker of impaired stemness
}

\author{
SUBATHRA RADHAKRISHNAN ${ }^{1,2}$, OMANA ANNA TRENTZ ${ }^{3}$, CATHERINE ANN MARTIN ${ }^{1,4}$, \\ METTU SRINIVAS REDDY ${ }^{1,5}$, MOHAMED RELA ${ }^{1,5}$, MARIMUTHU CHINNARASU ${ }^{5}$, \\ NARAYANA KALKURA ${ }^{4}$ and SHANMUGAAPRIYA SELLATHAMBY ${ }^{2}$
}

\author{
${ }^{1}$ National Foundation for Liver Research, Cell Laboratory, Gleneagles Global Health City, Chennai 600100; \\ ${ }^{2}$ Department of Biomedical Science, Bharathidasan University, Tiruchirappalli 620024; ${ }^{3} \mathrm{MIOT}$ Institute of Research, \\ MIOT International, Chennai 600089; ${ }^{4}$ Crystal Growth Centre, Anna University, Chennai 600025; ${ }^{5}$ Institute of \\ Liver Disease and Transplantation, Gleneagles Global Health City, Chennai 600100, India
}

Received September 7, 2018; Accepted April 9, 2019

DOI: $10.3892 / \mathrm{mmr} .2019 .10268$

\begin{abstract}
Infrapatellar fat pad-derived stem cells (IFPSCs) are emerging as an alternative to adipose tissue-derived stem cells (ADSCs) from other sources. They are a reliable source of autologous stem cells obtained from medical waste that are suitable for use in cell-based therapy, tissue engineering and regenerative medicine. Such clinical applications require a vast number of high-quality IFPSCs. Unlike embryonic stem cells (ESCs), ADSCs and IFPSCs have limited population doubling capacity; however, in vitro expansion of primary IFPSCs through multiple passages (referred to as $\mathrm{P}$ ) is a crucial step to acquire the desired population of cells. The present study investigated the effect of multiple passages on the stemness of IFPSCs during expansion and the possibility of predicting the loss of stemness using certain markers. IFPSCs were isolated from infrapatellar fat pad tissue resected during knee arthroplasty performed on aged patients ( $>65$ years old). These cells from the stromal vascular fraction were serially passaged to at least to $\mathrm{P} 7$, and their stemness characteristics were examined at each passage. It was observed that IFPSCs maintained their spindle-shaped morphology, self-renewability and homogeneity at P2-4. Furthermore, immunostaining revealed that these cells expressed mesenchymal stem cell (CD166, CD90 and CD105) and ESC markers [Sox2, Nanog, Oct4 and nucleostemin (NS)], whereas the hematopoietic stem cell marker CD45 was absent. These cells were also able to differentiate into the three germ layer cell types, thus
\end{abstract}

Correspondence to: Dr Shanmugaapriya Sellathamby, Department of Biomedical Science, Bharathidasan University, Palkalaiperur, Tiruchirappalli 620024, India

E-mail: shaniya_99@yahoo.com

Key words: infrapatellar fat pad, nucleostemin, stemness, spontaneous neurogenic differentiation confirming their ability to generate clinical grade cells. The findings indicated that prolonged culture of IFPSCs $(\mathrm{P}>6)$ led to the loss of the stem cell proliferative marker NS, with an increased population doubling time and progression toward neuronal differentiation, acquiring a neurogenic phenotype. Additionally, IFPSCs demonstrated an inherent ability to secrete neurotrophic factors and express receptors for these factors, which is the cause of neuronal differentiation at later passages. Therefore, these findings validated NS as a prognostic indicator for impaired stemness and identified IFPSCs as a promising source for cell-based therapy, particularly for neurodegenerative diseases.

\section{Introduction}

Adipose tissue-derived stem cells (ADSCs), with their multilineage mesodermal, neuroectodermal and definitive endodermal potential, may be an alternative to the use of pluripotent embryonic stem cells (ESCs) in the lab and clinical practice. Due to the easy availability and expandable nature of ADSCs, these cells are widely used as a source of autologous adult stem cells in regenerative medicine and tissue engineering $(1,2)$. The Hoffa pad/infrapatellar fat pad (IFP) tissue is emerging as a new source of ADSCs, termed infrapatellar fat pad-derived stem cells (IFPSCs), which can be obtained arthroscopically or from knee arthroplasty. It is important to highlight the features of this specific adipose tissue, which is elastic and highly innervated with nerve fibers and, therefore, associated with anterior knee pain during damage or inflammation (3). The majority of the progenitor cells are believed to reside in the stromal vascular fraction (SVF) of this adipose tissue (4). An important feature of ADSCs is their immunomodulatory effects and their ability to secrete growth factors. Our previous studies have reported the expression of ESC markers by IFPSCs, the neurogenic potential of IFPSCs, and the surface characterization of bone-derived osteoclast and IFPSCs-derived osteogenic cells (5-7), demonstrating their stemness and differentiation potential. Therefore, IFPSCs 
may be an important source of cells for autologous cell-based therapies used in regenerative medicine $(4,7)$.

Obtaining a sufficient number of cells for cellular therapy and tissue engineering applications requires ex vivo expansion of IFPSCs. Certain studies have reported the use of vast numbers of mesenchymal stem cells (MSCs) for cellular therapy, which required $>10$ weeks of expansion (8); however, sequential cell passaging has been demonstrated to result in the loss of proliferative, clonogenic and differentiation potential $(9,10)$. Though numerous studies have used ADSCs for tissue engineering applications, not all laboratories use the same isolation procedure and passage number. Few studies have compared the characteristics and differentiation potential of IFPSCs (11); thus, it is important to determine the consistency of the stemness during ex vivo expansion of IFPSCs to enable their application in tissue engineering.

In the current study, the serial changes in the expression of stem cell markers were investigated in IFPSCs, and the correlation of markers with the stemness of these cells was assessed to identify the ideal time point for cell differentiation and cell therapy applications. Prolonged culture and maintenance of IFPSCs beyond P6 resulted in the loss of stemness and the ability to differentiate into neuronal cells, due to autocrine/paracrine signaling mediated by secreted neurotrophic factors. Large-scale ex vivo expansion of cells without compromising pluripotency and long-term self-renewing capacity is required for efficient cell-based therapies.

\section{Materials and methods}

Ethical approval. Written informed consent was obtained from patients prior to enrollment in the present study. All the procedures were conducted in accordance with the guidelines of the Institutional Ethical Committee and the Institutional Committee for Stem Cell Research of MIOT Institute of Research and National Foundation of Liver Research, Cell Laboratory, Gleneagles Global Health City.

Isolation and culture of IFPSCs. Human IFP tissue was obtained from 6 patients (4 females and 2 males), with an age ranging between 65 and 68 years and a mean ( \pm standard error) age of $66.16 \pm 1.16$ years. The fat tissue was washed with Dulbecco's phosphate-buffered saline (DPBS) without calcium and magnesium (Gibco; Thermo Fisher Scientific, Inc., Waltham, MA, USA) to remove the blood. Small vessels and fascia were separated from the fat tissue. Isolated fat tissue was minced and stored in a sterile 50-ml tube with 7-10 ml (depending on the quality of the tissue) of $0.075 \%$ collagenase type I (PAN-Biotech, Aidenbach, Germany) dissolved in DPBS and digested at $37^{\circ} \mathrm{C}$ for $12 \mathrm{~h}$. An equal volume of Dulbecco's modified Eagle's medium (DMEM; Thermo Fisher Scientific, Inc.) was added to the enzyme-digested tissue and filtered through a 70- $\mu \mathrm{m}$ mesh filter (BD Biosciences, Franklin, Lakes, NJ, USA) to remove any debris. Following centrifugation of the filtrate at $489 \times \mathrm{g}$ for $8 \mathrm{~min}$ at $4^{\circ} \mathrm{C}$, the pellets (containing the SVF) were plated onto cell culture dishes $\left(58 \mathrm{~cm}^{2}\right.$; Cellstar ${ }^{\circledR}$; Greiner Bio-One GmbH, Frickenhausen, Germany) in DMEM with $10 \%$ fetal bovine serum (FBS) and $60 \mu \mathrm{g} / \mathrm{ml}$ antibiotic-antimycotic mixture (Invitrogen;
Thermo Fisher Scientific, Inc.) (7). This stage of the primary cell culture was considered as passage $0(\mathrm{P} 0)$, and cells were cultured until $100 \%$ confluency was reached. The cells were then detached using EDTA with $0.25 \%$ trypsin (Invitrogen; Thermo Fisher Scientific, Inc.) and counted. Subsequently, $5 \times 10^{5}$ cells were further seeded in culture dishes $\left(58 \mathrm{~cm}^{2}\right)$ and cultured for 7 days (P1). This procedure was repeated until $\mathrm{P} 8$ and the time points associated with the different passages were as follows: P0, days 0-7; P1, days 7-14; P2, days 14-21; P3, days 21-28; P4, days 28-35; P5, days 35-42; P6, days 42-49; and P7, days 49-56. In between each passage, the total cell number in the culture dish was calculated to monitor the proliferation index. Phase contrast images were captured using a Nikon binocular inverted microscope (model TS100 F; Nikon Corporation, Tokyo, Japan).

Proliferation analysis. For proliferation analysis, $5 \times 10^{5}$ cells of each passage were plated onto $100-\mathrm{mm}$ dishes in triplicate. Cells were trypsinized when $100 \%$ confluency (after 7 days) was reached, and live cells were counted using trypan blue dye exclusion assay in a hemocytometer. The population doubling time (PDT) was calculated with the following equation:

$$
T_{C}=\frac{0.3 T}{\log \left(\frac{A}{A_{0}}\right)}
$$

Where $T_{\mathrm{C}}$ is the PDT, $T$ is the incubation time in any units [in the present study, time is in day(s)], $\mathrm{A}$ is the final cell number, and $\mathrm{A}_{0}$ is the initial cell number used for seeding (12).

Differentiation of three germ layers. IFPSCs from P2 $(n=2)$ were used in the present study. The cells were divided into three groups, and appropriate protocols were followed for neuroectodermal, definitive endodermal and mesodermal osteogenic induction, as described later in the text. The IFPSC-derived differentiated cells were then examined for the expression of germ layer-specific molecular markers using reverse transcription-polymerase chain reaction (RT-PCR) and immunocytochemistry.

Neuroectodermal induction. Stem cells at P2 were collected and differentiated to neural lineage using basic fibroblast growth factor (bFGF; Thermo Fisher Scientific, Inc.) in serum-free DMEM. The cells were continuously exposed to $20 \mathrm{ng} / \mathrm{ml} \mathrm{bFGF}$ for 2 weeks, after which intermittent exposure was used to maintain the neuronal culture.

Definitive endodermal induction. Stem cells at P2 were preconditioned with Iscove's modified Dulbecco's medium (IMDM; Gibco; Thermo Fisher Scientific, Inc.) containing $20 \mathrm{ng} / \mathrm{ml}$ epidermal growth factor and $10 \mathrm{ng} / \mathrm{ml} \mathrm{bFGF,} \mathrm{following} \mathrm{which}$ they were differentiated into hepatocytes using a two-step protocol (13). The cells were then treated with differentiation medium, consisting of IMDM supplemented with $20 \mathrm{ng} / \mathrm{ml}$ hepatocyte growth factor (Thermo Fisher Scientific, Inc.), $10 \mathrm{ng} / \mathrm{ml} \mathrm{bFGF}$ (Thermo Fisher Scientific, Inc.) and $0.61 \mathrm{~g} / 1$ nicotinamide (Sigma-Aldrich; Merck KGaA) for 7 days. Subsequently, cells were transferred to maturation medium, consisting of IMDM with $20 \mathrm{ng} / \mathrm{ml}$ oncostatin $\mathrm{M}, 1 \mu \mathrm{mol} / \mathrm{l}$ dexamethasone and $50 \mathrm{mg} / \mathrm{ml}$ insulin-transferrin-selenium 
mix (all from Thermo Fisher Scientific, Inc.). The obtained cells were maintained in this medium (13).

Mesodermal osteogenic induction. Stem cells at P2 were collected for osteocyte differentiation as described by Zuk et al (1). Cells were maintained in osteogenic culture medium, consisting of DMEM with $10 \%$ FBS, $0.1 \mu \mathrm{M}$ dexamethasone, $10 \mathrm{mM} \beta$-glycerophosphate (Thermo Fisher Scientific, Inc.) and $60 \mu \mathrm{g} / \mathrm{ml}$ ascorbic acid (Sigma-Aldrich; Merck KGaA) for 14 days.

Immunocytochemical assay. Analysis of stem cell markers in early passages (P1-4) and neuronal-specific markers in later passages $(\mathrm{P}>6)$ was performed using specific antibodies against the stem cell, germ layer and neuron-specific markers. IFPSCs from day $14(\mathrm{P} 2)$, day $28(\mathrm{P} 4)$ and day $48(\mathrm{P}>6)$ were cultured on sterile glass coverslips and fixed in $4 \%$ paraformaldehyde. The cells were washed three times in washing buffer (DPBS), permeabilized with $0.2 \%$ Triton X-100 in DPBS, washed for a further three times and then incubated in blocking buffer containing $1 \%$ bovine serum albumin in DPBS for $1 \mathrm{~h}$. Cells were washed three times in washing buffer and incubated overnight with the primary antibody. Subsequently, the cells were washed extensively with washing buffer and incubated for $2 \mathrm{~h}$ in the appropriate fluorescein isothiocyanate-conjugated secondary antibody (goat anti-mouse and donkey anti-goat IgG; Santa Cruz Biotechnology, Inc., Dallas, TX, USA). The cells were then washed three times with washing buffer and mounted in aqueous mounting medium. The markers used for stem cell characterization included nucleostemin (NS), CD166, Nanog, CD105 and CD13. The pan-neural markers used in the present study were neuron-specific enolase (NSE), neurofilament-L (NF-L), growth-associated protein 43 (GAP43), synaptosomal-associated protein 25 (SNAP25), syntabulin, oligodendrocyte transcription factor 2 (Olig2) and microtubule-associated protein 2 (MAP2). The primary and secondary antibodies used in this study are listed in Table I. Images were captured using a Nikon binocular inverted microscope (model TS100 F; Nikon Corporation).

Flow cytometry. Stem cell characterization and differential expression at P2 and P3 were examined using flow cytometric analysis. Briefly, cells from P2 and P3 (early passages) were harvested using trypsin-EDTA digestion, centrifuged at $489 \mathrm{x} \mathrm{g}$ for $8 \mathrm{~min}$ at $4^{\circ} \mathrm{C}$ and re-suspended at a concentration of $10^{6}$ cells $/ \mathrm{ml}$ in DMEM $/ 2 \%$ FBS. Aliquots containing $10^{5}$ cells were incubated with individual surface antigen-specific fluorescent-labeled antibodies (Table II) for $30 \mathrm{~min}$ at room temperature, and cells were then washed in PBS containing $2 \%$ FBS. For the analysis of the intracellular proteins nestin and SRY-box 2 (Sox2), permeabilization medium (Intra prep; Beckman Coulter, Inc., Brea, CA, USA) was used prior to the addition of the primary antibody. Finally, the cells were fixed in $10 \%$ formalin prepared in PBS containing 2\% FBS, and analyzed using a flow cytometer (Beckman Coulter flow cytometry system with CXP software analysis; Beckman Coulter, Inc., Brea, CA, USA).

Stem cell characterization. The analysis of surface epitope patterns and stem cell marker proteins can aid the isolation and characterization of IFPSCs. For stem cell characterization, cells from incubation day 14 (P2) were used. The cells were screened for MSC markers (CD90, CD166 and CD105), an ESC marker (Sox2), a hematopoietic stem cell (HSC) marker (CD45) and an early neuronal marker (nestin) using flow cytometry analysis.

Differential expression analysis between passages. As small neurite extensions appeared between P4 and P5, nestin, an intermediate filament protein that is expressed in dividing cells during the very early stages of development in the central nervous system $(14,15)$, was also screened along with two MSC markers (CD90 and CD166) in early passages of homogenous IFPSCs (P2 and P3). As CD105 and Sox2 were expressed in IFPSCs and in differentiating neurons, they were not considered for further examination. IFPSCs in later passages (P6) had a similar morphology to neuronal cells. $\beta$-tubulin III, a neuron-specific protein used to confirm the neuronal commitment, was screened in early and late passages of IFPSCs (P3 and P6).

$R T$-PCR detection. Semi-quantitative gene expression analysis was performed using RT-PCR for stem cells, spontaneously differentiated stem cells without external stimuli and stem cells with external stimuli-induced differentiation. Briefly, RNA samples were isolated using a Qiagen kit (Qiagen $\mathrm{GmbH}$, Hilden, Germany) as per the manufacturer's recommendations. RNA purity was confirmed by determining the 260/280 nm absorbance ratio, and it was quantified using the Bio Photometer D30 (Eppendorf, Hamburg, Germany). A total of $1 \mu \mathrm{g}$ RNA was then reverse transcribed into cDNA using Omniscript ${ }^{\circledR}$ Reverse Transcriptase (Qiagen GmbH), as described in the kit protocol. The reaction was performed at $37^{\circ} \mathrm{C}$ for $60 \mathrm{~min}$ in a Master Cycler Pro-S (Eppendorf). The samples selected for cDNA synthesis were highly pure, with a 260/280 ratio between 1.8 and 2.0. Each reaction was prepared in a total reaction mixture of $20 \mu \mathrm{l}$, containing $1 \mu \mathrm{g}$ total RNA. Subsequently, PCR amplification was performed using primers specifically designed to amplify human NS, Nanog, neurotrophic receptor tyrosine kinase 1 (NTRK1), octamer-binding transcription factor 4 (Oct4), Sox2, CD105 and CD166 mRNA transcripts. A total of $3 \mu \mathrm{l}$ R product (cDNA) and the HotStarTaq ${ }^{\circledR}$ Master Mix PCR kit (Qiagen $\mathrm{GmbH}$ ) were used for PCR in a total volume of $25 \mu \mathrm{l}$, according to the manufacturer's protocol. The thermal cycler was programmed according to the manufacturer's instructions. The PCR strips were placed into the thermal cycler, and the cycling program was started. Following amplification, the samples were stored at $4^{\circ} \mathrm{C}$, or at $-30^{\circ} \mathrm{C}$ to $-15^{\circ} \mathrm{C}$ for longer-term storage. GAPDH was used as an endogenous control. All the primer sequences were determined using established gene sequences and are listed in Table III. PCR products were separated by $1.5 \%$ Ultra-pure agarose gel electrophoresis (Thermo Fisher Scientific, Inc.) and DNA was visualized using ethidium bromide $(20 \mu \mathrm{l})$. Semi-quantification of RT-PCR was conducted using ImageJ software (version 1.52a; National Institutes of Health, Bethesda, MD, USA) and results were normalized to GAPDH. The data were analyzed using GraphPad Prism software (version 8; GraphPad Software, Inc., La Jolla, CA, USA). 
Table I. Antibodies used in immunocytochemistry.

\begin{tabular}{|c|c|c|c|c|}
\hline Antibody & Antibody host ${ }^{\mathrm{a}}$ & IgG isotype & Supplier & Cat. no. \\
\hline \multicolumn{5}{|l|}{ Primary } \\
\hline CD166 & Goat & $\operatorname{IgG}$ & Santa Cruz Biotechnology, Inc. & sc-74558 \\
\hline Nanog & Goat & $\operatorname{IgG}_{1}$ & Santa Cruz Biotechnology, Inc. & sc-293121 \\
\hline Nucleostemin & Mouse & $\mathrm{IgG}$ & Santa Cruz Biotechnology, Inc. & sc- 166460 \\
\hline CD105 & Mouse & $\operatorname{IgG}$ & Santa Cruz Biotechnology, Inc. & sc-71042 \\
\hline CD13 & Mouse & $\operatorname{IgG}$ & Santa Cruz Biotechnology, Inc. & sc- 166270 \\
\hline NSE & Mouse & $\operatorname{IgG}_{1}$ & Santa Cruz Biotechnology, Inc. & sc-21738 \\
\hline NF-L & Mouse & $\mathrm{IgG}_{1}$ & Santa Cruz Biotechnology, Inc. & sc-71678 \\
\hline SNAP25 & Goat & $\operatorname{IgG}$ & Santa Cruz Biotechnology, Inc. & sc-7538 \\
\hline GAP43 & Goat & $\operatorname{IgG}$ & Santa Cruz Biotechnology, Inc. & sc-7457 \\
\hline MAP2 & Mouse & $\mathrm{IgG}$ & Santa Cruz Biotechnology, Inc. & sc-135979 \\
\hline Syntabulin & Mouse & $\operatorname{IgG}$ & Santa Cruz Biotechnology, Inc. & sc-87447 \\
\hline Olig2 & Goat & IgG1 & Santa Cruz Biotechnology, Inc. & sc-19967 \\
\hline Collagen I & Mouse & IgG1 & Santa Cruz Biotechnology, Inc. & sc-59772 \\
\hline Sox 17 & Mouse & $\operatorname{IgG} 2 b, \kappa$ & BioLegend & 698501 \\
\hline \multicolumn{5}{|l|}{ Secondary } \\
\hline Donkey anti-goat IgG-FITC & Donkey & $\operatorname{IgG}$ & Santa Cruz Biotechnology, Inc. & sc-2024 \\
\hline Mouse anti-goat IgG-FITC & Mouse & $\operatorname{IgG}_{1}$ & Santa Cruz Biotechnology, Inc. & sc-2356 \\
\hline m-IgGkBP-FITC & - & $\mathrm{IgG}$ & Santa Cruz Biotechnology, Inc. & sc-516140 \\
\hline Goat anti mouse IgG-FITC & Goat & $\operatorname{IgG}$ & Santa Cruz Biotechnology, Inc. & sc-2010 \\
\hline
\end{tabular}

${ }^{a}$ Host in which the antibody was generated. NSE, neuron-specific enolase; GAP43, growth-associated protein 43; NF-L, neurofilament-L; SNAP25, synaptosomal-associated protein 25; Olig2, oligodendrocyte transcription factor 2; MAP2, microtubule-associated protein 2; Sox 17, SRY-box 17; FITC, fluorescein isothiocyanate.

Table II. Antibodies used in flow cytometric analysis.

\begin{tabular}{|c|c|c|c|}
\hline Antibody & Manufacturer & Cat. no. & $\begin{array}{c}\text { Antibody volume }(\mu 1) / 100 \mu 1 \\
\text { cell suspension }\end{array}$ \\
\hline FITC anti-human CD45 & BioLegend & 368507 & 5 \\
\hline APC anti-human CD105 & BioLegend & 323207 & 5 \\
\hline PE anti-human Sox2 & BioLegend & 656103 & 5 \\
\hline Alexa Fluor 488 anti-human $\beta$-tubulin III & Stemcell Technologies, Inc. & 60100AD.1 & 5 \\
\hline FITC anti-human CD90 & BioLegend & 328107 & 5 \\
\hline PE anti-human CD166 & BioLegend & 343903 & 5 \\
\hline Alexa Flour 488 anti-human nestin & Stemcell Technologies, Inc. & 60091AD.1 & 5 \\
\hline
\end{tabular}

Sox2, SRY-box 2; FITC, fluorescein isothiocyanate; PE, phycoerythrin; APC, allophycocyanin.

Stem cell characterization using RT-PCR detection. To analyze the expression pattern of stem cell markers in consecutive passages from days 14-42, total RNA samples were extracted from $100 \%$ confluent IFPSCs on days 14 (P2), 28 (P4) and 42 (P6), and subjected to RT-PCR.

Characterization of spontaneously differentiated neurons using RT-PCR detection. To analyze the expression of pan-neural markers of spontaneously differentiated neuronal cells, RNA was isolated from IFPSCs at days 14 (P2), 35 (P5) and 62 (P7). Subsequently, PCR amplification was performed using primers specifically designed to amplify human NSE, glial fibrillary acidic protein (GFAP) and midkine (MDK). GAPDH served as an endogenous control.

Characterization of differentiated stem cells (as three germ layers). IFPSC from day 14 (P2) served as a control in the characterization of stem cells differentiated into three germ layers. At the appropriate days after induction, total RNA was isolated from the induced groups to demonstrate the differentiation of the three germ layers. PCR amplification was performed using primers specifically designed to amplify human neuronal 
Table III. Oligonucleotide primers used in polymerase chain reaction.

\begin{tabular}{|c|c|}
\hline Genes & Primer sequences \\
\hline \multirow[t]{2}{*}{ Nanog } & F: 5'-gtcttctgctgagatgcctcaca-3' \\
\hline & R: 5'-cttctgcgtcacaccattgctat-3 \\
\hline \multirow[t]{2}{*}{ Nucleostemin } & F: 5'-gggaagataaccaagcgtgtg-3' \\
\hline & R: 5'-cctccaagaagtttccaaagg-3' \\
\hline \multirow[t]{2}{*}{ Oct4 } & F: 5'-gttgatcctcggacctggcta-3' \\
\hline & R: 5'-ggttgcctctcactcggttct-3' \\
\hline \multirow[t]{2}{*}{ Sox2 } & F: 5'-gccgagtggaaacttttgtcg-3' \\
\hline & R: 5'-gcagcgtgtacttatccttctt-3 \\
\hline \multirow[t]{2}{*}{ CD105 } & F: 5'-tgtctcacttcatgectcagct-3' \\
\hline & R: 5'-aggctgtccatgttgaggagt-3' \\
\hline \multirow[t]{2}{*}{ CD166 } & F: 5'-agataccattatcatcataccttgccgact-3' \\
\hline & $\mathrm{R}: 5^{\prime}$-tgtctttgtattcgtgtacatcgtcg-3' \\
\hline \multirow[t]{2}{*}{ NSE } & $\mathrm{F}: 5^{\prime}$-ctgatgctggagttggatgg-3' \\
\hline & R: 5'-ccattgatcacgttgaaggc-3' \\
\hline \multirow[t]{2}{*}{ NF-L } & F: 5'-tcctactacaccagccatgt-3' \\
\hline & $\mathrm{R}: 5^{\prime}$-tccccagcaccttcaacttt-3' \\
\hline \multirow[t]{2}{*}{ MDK } & F: 5'-cgactgcaagtacaagtttgagaac-3' \\
\hline & R: 5'-tctcctggcactgagcattg-3' \\
\hline \multirow[t]{2}{*}{ GFAP } & F: 5'-cctctccctggctcgaatg-3' \\
\hline & R: 5'-ggaagcgaaccttctcgatgta-3' \\
\hline \multirow[t]{2}{*}{ Collagen I } & F: 5'-gcgagagcatgaccgatgga-3' \\
\hline & R: 5'-gcggatctcgatctcgttgga-3' \\
\hline \multirow[t]{2}{*}{ CBFA1 } & F: 5'-cagaccagcagcactccata-3' \\
\hline & R: 5'-ttcaatatggtcgccaaaca-3' \\
\hline \multirow[t]{2}{*}{ Osteocalcin } & F: 5'-atgagagccetcacactcctc-3' \\
\hline & R: 5'-gccgtagaagcgccgataggc-3' \\
\hline \multirow[t]{2}{*}{ RANKL } & F:5'-gggaattacaaagtgcaccag-3' \\
\hline & R: 5'-ggtcgggcaattctgaatt-3' \\
\hline \multirow[t]{2}{*}{ TAT } & F: 5'-tgagcagtctgtccactgcc-3' \\
\hline & R: 5'-atgtgaatgaggaggatctgag-3' \\
\hline \multirow[t]{2}{*}{ TO } & F: 5'-atacagagacttcagggagc-3' \\
\hline & R: 5'-tggttgggttcatcttcggtat-3' \\
\hline \multirow[t]{2}{*}{ Albumin } & F: 5'-tgcttgaatgtgctgatgacagg-3' \\
\hline & R: 5'-aaggcaagtcagcaggcatctcatc-3' \\
\hline \multirow[t]{2}{*}{ GAPDH } & F: 5'-gggctgcttttaactctgct-3' \\
\hline & R: 5'-tggcaggtttttctagacgg-3' \\
\hline
\end{tabular}

bp

Oct4, octamer-binding transcription factor 4; NSE, neuron-specific enolase; NF-L, neurofilament-L; MDK, midkine; GFAP, glial fibrillary acidic protein; CBFA1, core-binding factor subunit $\alpha-1$; RANKL, receptor activator of nuclear factor- $\kappa \mathrm{B}$ ligand; TAT, tyrosine aminotransferase; TO, tryptophan 2,3-dioxygenase.

markers (NSE, NF-L and MDK), hepatocyte markers [tyrosine aminotransferase (TAT), tryptophan 2,3-dioxygenase (TO) and albumin], osteogenic markers [collagen I, core-binding factor subunit $\alpha-1$ (CBFA1), osteocalcin and receptor activator of nuclear factor- $\kappa \mathrm{B}$ ligand (RANKL)] and GAPDH.

Western blot analysis. Reduced expression of NS at later passages was examined using western blot analysis. Protein samples were extracted from $100 \%$ confluent IFPSCs on days 14 (P2), 28 (P4) and 42 (P6). Briefly, IFPSCs were rinsed three times with ice-cold DPBS, then lysed in $300 \mu \mathrm{l}$ cold RIPA buffer (containing $50 \mathrm{mM}$ Tris- $\mathrm{HCl}, \mathrm{pH} 7.4,150 \mathrm{mM}$ $\mathrm{NaCl}, 2$ mM EDTA, $1 \%$ Nonidet P-40 and 0.1\% SDS) and kept on ice for $30 \mathrm{~min}$ with occasional swirling to enable uniform spreading. The cell lysate was collected using a cell scraper and centrifuged at $2,770 \mathrm{x}$ g for $30 \mathrm{~min}$ at $4^{\circ} \mathrm{C}$, and the supernatant was stored at $-71^{\circ} \mathrm{C}$. Total protein concentration was measured using the Lowry method. Next, protein $(35-40 \mu \mathrm{g})$ was loaded into each well of a $10 \%$ SDS gel and electrophoresed. Electrophoresed bands from polyacrylamide gels were then transferred to a nitrocellulose membrane. The membranes were blocked for $2 \mathrm{~h}$ at room temperature with skimmed milk powder, washed and probed with specific primary antibodies overnight at $4^{\circ} \mathrm{C}$ (1:500 dilutions). Affinity-purified mouse monoclonal antibody for NS (cat. no. sc-166460) and mouse monoclonal antibody specific for GAPDH (cat. no. sc-47724) were used as the primary antibodies. Following washing, the membranes were incubated with horseradish peroxidase-conjugated goat anti-mouse IgG (cat. no. sc-2005) secondary antibody for $2 \mathrm{~h}$ at room temperature $(1: 1,000)$. All primary and secondary antibodies were purchased from Santa Cruz Biotechnology, Inc. Subsequent to washing three times with DPBS/0.1\% Tween, the blots were developed using an enhanced chemiluminescence kit (GE Healthcare, Chicago, IL, USA). Semi-quantification was conducted by measuring band intensity in developed X-ray films using ImageJ software (version 1.52a; National Institute of Health) and results were normalized to GAPDH (16). Data were analyzed using GraphPad Prism software (version 8; GraphPad Software, Inc.).

Characterization of conditioned medium secreted by IFPSCs. A marked difference in the expression of markers was observed at P3, and neurotrophic factors may be secreted by IFPSCs in early passage (P2) in the discarded medium. Therefore, medium collected at P2 was used for biophysical characterization. When the cells reached confluence, the medium was changed to serum-free DMEM, and IFPSCs were maintained in this medium for $72 \mathrm{~h}$. Subsequently, conditioned media were collected from IFPSCs using Amicon Ultra-15 Centrifugal Filter Units 3000 at molecular weight cutoffs. Conditioned medium was subjected to biophysical characterization to analyze the functional groups present and to compare them with neurotrophic factor-specific peaks using a Fourier transform infrared (FTIR) spectrometer (FTIR-6300; JASCO International Co., Ltd., Tokyo, Japan). The data obtained were analyzed using the Origin Pro 8.0 software (Origin Lab Corporation, Northampton, MA, USA), and the graph was plotted.

Statistical analysis. All experiments were performed at least three times independently. The proliferation analysis experiment was also performed in triplicate. The data were analyzed using GraphPad Prism software (version 7; GraphPad Software, Inc.) and subjected to one-way analysis of variance with post-hoc Tukey test to determine the significant difference of PDT between P1, P3 and P6. Data are presented as the mean \pm standard error of the mean. $\mathrm{P}<0.05$ was considered to indicate a statistically significant difference. 


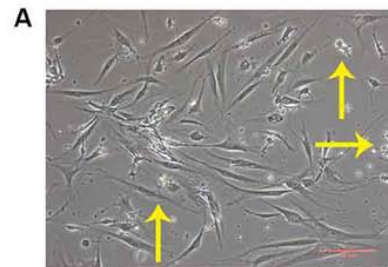

Passage 0 Day 1

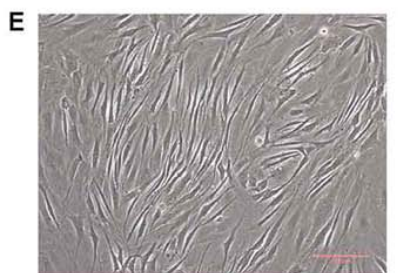

Passage 3 Day 23

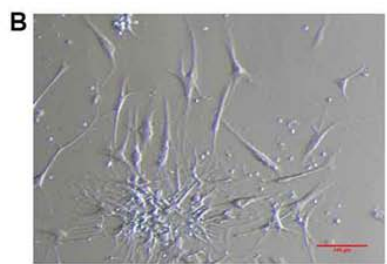

Passage 0 Day 4

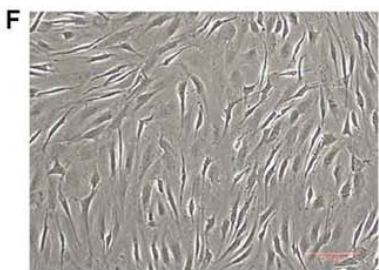

Passage 4 Day 28

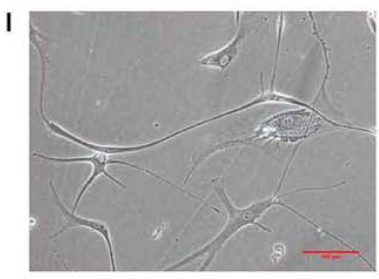

Passage 7 Day 51

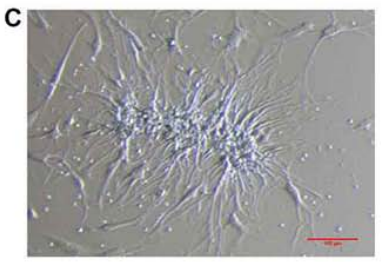

Passage 0 Day 6

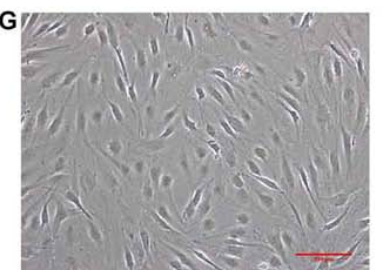

Passage 5 Day 37

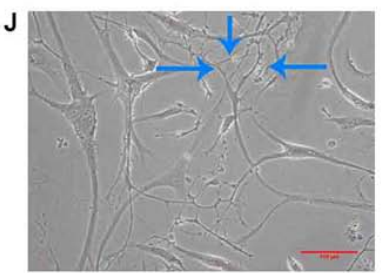

Passage 8 Day 56

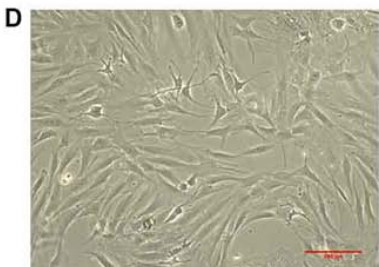

Passage 2 Day 14

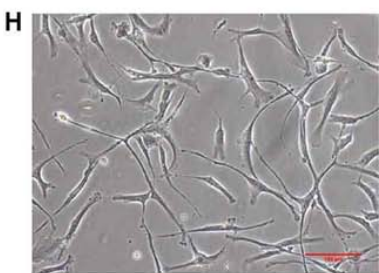

Passage 6 Day 44

Figure 1. Morphological assessment of infrapatellar fat pad-derived stem cells between day 1 (P0) and day 56 (P8) at a magnification of x10. (A) On day 1, adherent and non-adherent cells were observed (yellow arrows indicate the three different types of cells). (B) Adherent cells started forming small colonies at day 4; (C) these colonies expanded at day 6 and reached confluence at day 7. (D) A homogenous monolayer of stem cell culture with unique fibroblast structure was observed at day $14(\mathrm{P} 2)$. (E) Thin fibroblast structures were seen at P3 day 23. (F) The characteristic spindle-shaped structure was maintained until P4 day 28. (G) Cell began to lose these features at P5. (H) Cells became thin and long, with small neurite projections were observed. (I) Cells with long neurite projections were observed at P7 day 51. (J) The projections extended to form interconnections similar to dendrite and axonal outgrowth of neurons at P8 day 56 (blue arrows indicate the interconnected cells). Scale bar, $100 \mu \mathrm{m}$.

\section{Results}

Loss of fibroblast morphology on sequential passaging. Morphological analysis revealed that the stem cells lost their fibroblast morphology and acquired neural lineage cell morphology following sequential passaging. At day 0 (P0), cells obtained from SVF were not uniform and contained both adherent and non-adherent cells, appearing as a mixed culture containing morphologically different types of cells (Fig. 1A). At day 4 (P0), IFPSCs formed small colonies and were densely distributed with a spindle-shaped morphology (Fig. 1B). The colonies continued to grow (Fig. 1C) and reached confluence on day 7. Following two passages, IFPSCs formed a homogenous population of fibroblast-like spindle-shaped cells forming a monolayer, and all the cells adhered to the surface of the culture dish (Fig. 1D). After P4, the cells became very thin, but maintained fibroblast-like structures. No significant difference was observed in cell growth until day 35 (Fig. 1E, F). The spindle-shaped cells observed initially (P2-4) began to differentiate toward neuronal lineage, exhibiting neurite-like projections at P5 between days 35 and 42 (Fig. 1G). It was observed that the differentiation of IFPSCs toward a neurogenic phenotype occurred without any induction at later passages (after P5). Cells became long and thin, with prominent neurite outgrowth, and the cell body consisted of a nucleus and two or more fibers interlinked with each other (Fig. 1H-J). Thus, the results indicated that IFPSCs remained undifferentiated until day 35 of culture.
P2 IFPSCs express MSC markers and morphologically resemble MSCs. Flow cytometric analysis of $\mathrm{P} 2$ cells, which were cultured and expanded in the absence of any induction stimuli, revealed that the undifferentiated stromal cells were consistently positive for a number of MSC surface markers, including CD105 (82.2\%), CD166 (100\%) and CD90 (100\%), whereas they were negative for nestin and the HSC marker CD45 (0\%). These cells also expressed the transcription factor Sox2 (92.3\%; Fig. 2A). In addition, immunocytochemical analysis revealed the positive expression of stem cell markers, including NS, Nanog, CD166, CD105 and CD13, in these cells (Fig. 2B). NS is a proliferative stromal cell marker, whereas CD105 and CD166 serve a crucial role in stem cell maintenance. It was observed that CD13, a multifunctional aminopeptidase cell surface molecule involved in stem cell maintenance, was densely expressed on P2 IFPSCs. Taken together, these results confirmed that the isolated IFPSCs exhibited MSC-like features with good initial viability, and high adherence and proliferation ability.

Increase in PDT at later passages reveals decreased proliferative index. The growth rate of IFPSCs was analyzed between days 14 (P2) and 49 (P7). For all passages, 5x10 cells were initially seeded in triplicates $(n=3)$. Fig. 3 presents a graphical representation of the PDT of IFPSCs in prolonged culture. P2 cells exhibited a lower PDT, indicating a high proliferative capacity. A gradual increase in PDT was observed after P4, and the cell number was reduced considerably by day 42 . These 
A

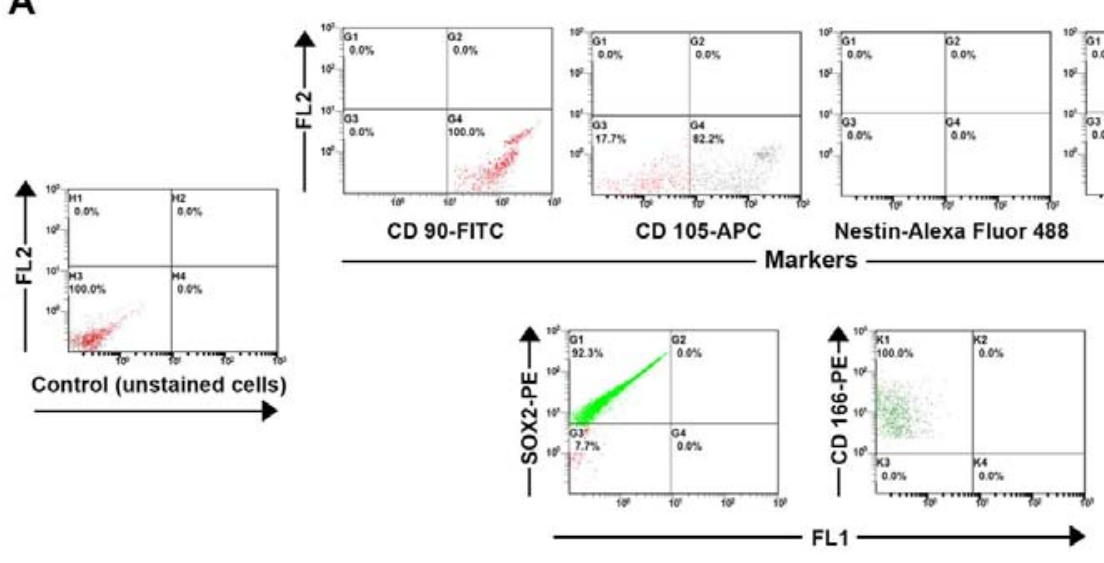

B

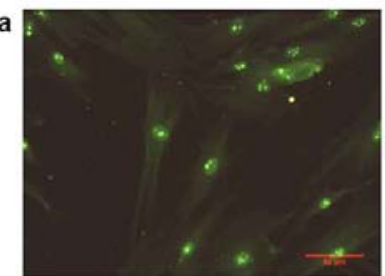

Nucleostemim

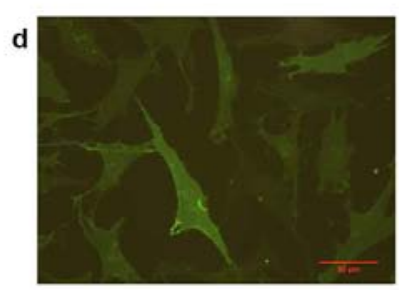

CD105

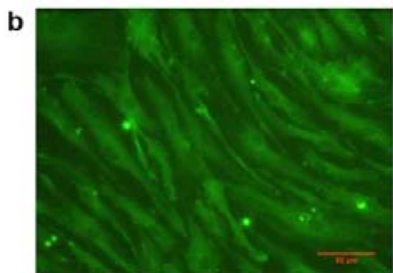

Nanog

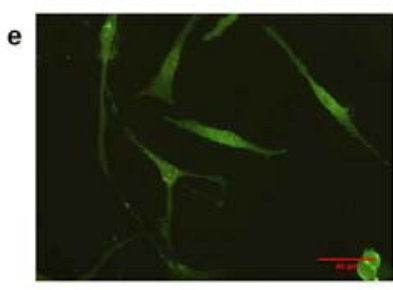

CD13

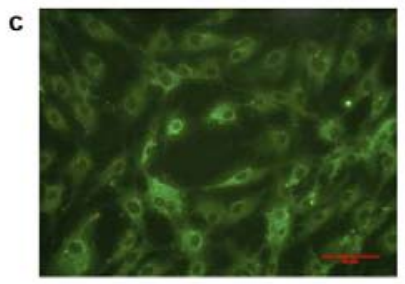

CD166

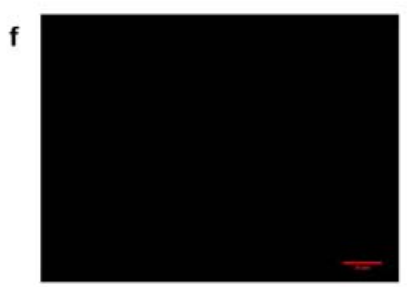

Negative Control

Figure 2. (A) Flow cytometric characterization of IFPSCs at day 14 (P2), with unstained cells serving as the negative control. The cells were characterized according to the surface antigen expression of CD90, CD105, CD166 and CD45, as well as the transcription factor Sox 2 and early neuronal marker nestin. (B) Immunocytochemical analysis of IFPSCs for stem cell markers at day 14 (P2; magnification, x20). FITC-stained images show the positive expression of the following stem cell-specific markers: (a) Nucleostemin, (b) Nanog, (c) CD166, (d) CD105 and (e) CD13, with (f) unstained cells serving as the negative control. Scale bar, $50 \mu \mathrm{m}$. IFPSCs, infrapatellar fat pad-derived stem cells; FITC, fluorescein isothiocyanate; PE, phycoerythrin; APC, allophycocyanin; Sox 2, SRY-box 2.

results were accompanied by changes in cell morphology at $>5$ passages (Fig. 1). At P6, the PDT was significantly increased when compared with that at $\mathrm{P} 2$ and $\mathrm{P} 3$ ( $\mathrm{P}<0.05$; Fig. 3$)$. Passages beyond P7 were also maintained, however, the growth rate could not be analyzed as the cells failed to reach $100 \%$ confluence even after 14 days in culture.

\section{IFPSCs exhibit reduced expression of the markers CD166 and} NS on increased passage. To analyze the stemness properties of IFPSCs during prolonged culture in consecutive passages at days $0-42$, the expression levels of several stem cell markers, including NS, Nanog, Oct4, GAPDH, CD105 and CD166, were analyzed in different passages of IFPSCs (P2-6) using RT-PCR. GAPDH served as the endogenous control in the experiment (Fig. 4A). As shown in Fig. 4B and 4E, significant differences in the mRNA levels of CD166 and NS markers were detected on P6 day 42 compared with on P2 day 14. Conversely, there was no significant difference in the expression levels of Nanog, Oct4 and CD105 (Fig. 4C, D and F). Reduced expression of CD166, which serves a crucial role in stem cell maintenance, and NS, a

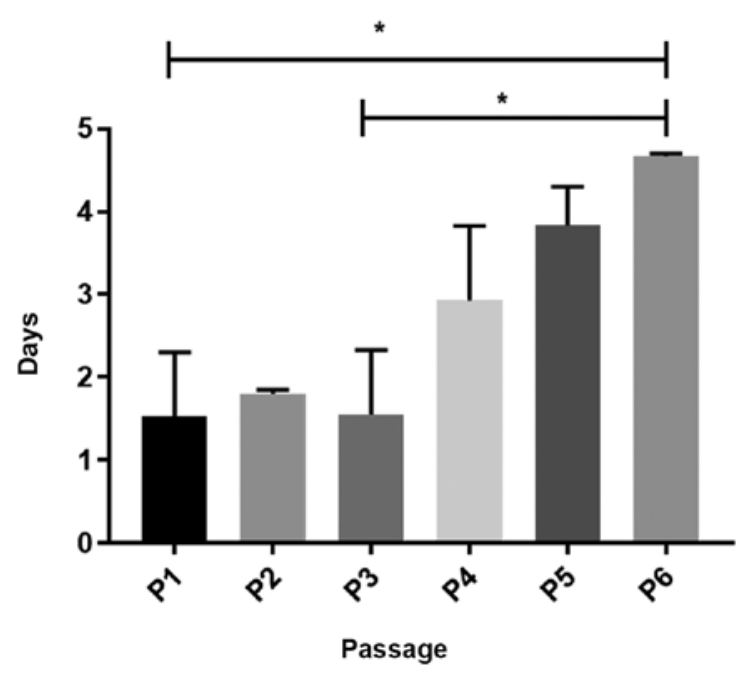

Figure 3. PDT of infrapatellar fat pad-derived stem cells in protracted culture $(n=3)$. The mean PDT increased with an increase in number of passages, and a significant increase was observed at P6 compared with P1 and P3 (one-way analysis of variance post-hoc Tukey test). Values are expressed as the mean \pm standard error of the mean. ${ }^{*} \mathrm{P}<0.05$. PDT, population doubling time. 

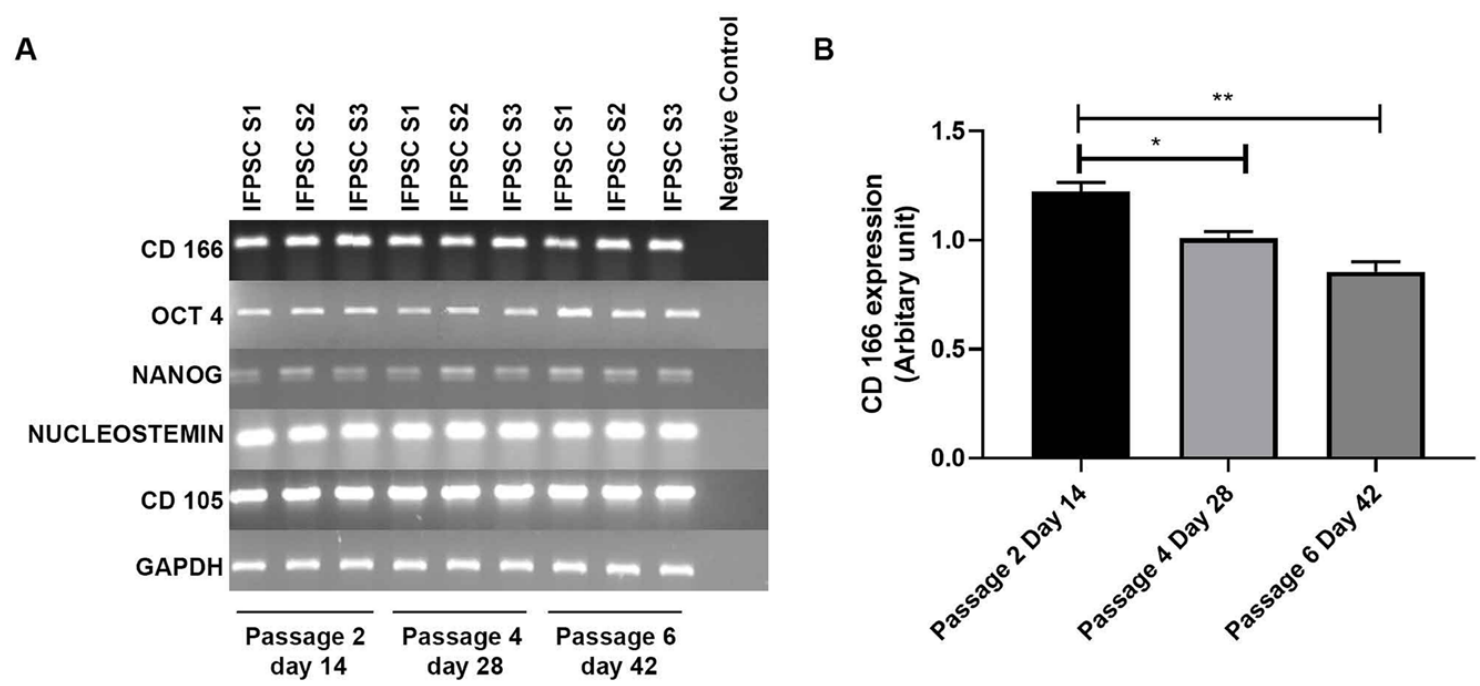

C
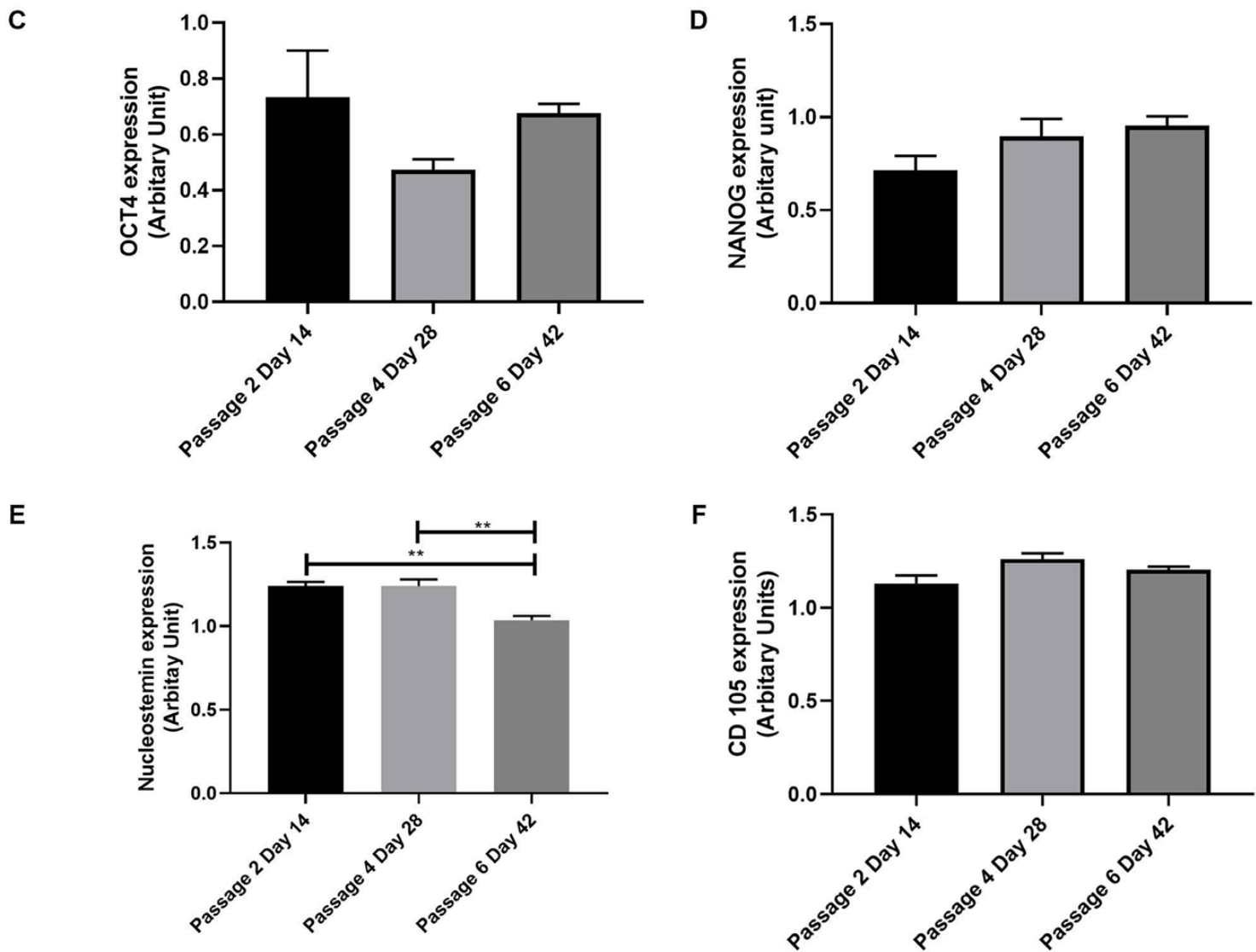

Figure 4. Stem cell-specific gene expression profile of IFPSCs examined by semi-quantitative reverse transcription-polymerase chain reaction analysis (n=3) at day 14 (P2), day 28 (P4) and day 42 (P6). GAPDH served as an endogenous-positive control (A) Transcriptionally (at the mRNA level), cells up to P6 exhibited positivity for all the stem cell markers tested. (B-F) Semi-quantification of reverse transcription-polymerase chain reaction was conducted using ImageJ software and results were normalized to GAPDH. Statistical analysis was conducted using one-way analysis of variance with post-hoc Tukey test. Values are expressed as the mean \pm standard error of the mean. ${ }^{*} \mathrm{P}<0.05$ and ${ }^{* *} \mathrm{P}<0.01$. IFPSC, infrapatellar fat pad-derived stem cell; Oct 4 , octamer-binding transcription factor 4.

stromal proliferation marker, clearly indicated that IFPSCs lose stemness properties on increased passage.

Expression of neuronal-specific markers in IFPSCs at later passages. As mentioned earlier, morphological analysis revealed changes in the cell structure toward a differentiated neuronal-like phenotype in cells at later passages $(\mathrm{P}>6)$. Therefore, immunocytochemical staining was subsequently performed to detect the expression of neural lineage markers, including GAP43, syntabulin, NSE, Snap25, NF-L, MAP2 and Olig2, in prolonged cultures of IFPSCs. Prolonged culturing of IFPSCs resulted in neural lineage marker expression, whereas IFPSCs from early passages were negative for neuronal markers (data not shown). As shown in Fig. 5A, GAP43, a protein associated with nerve growth, was expressed in the cytoplasm and was present in the dynamic nerve filaments. 
A
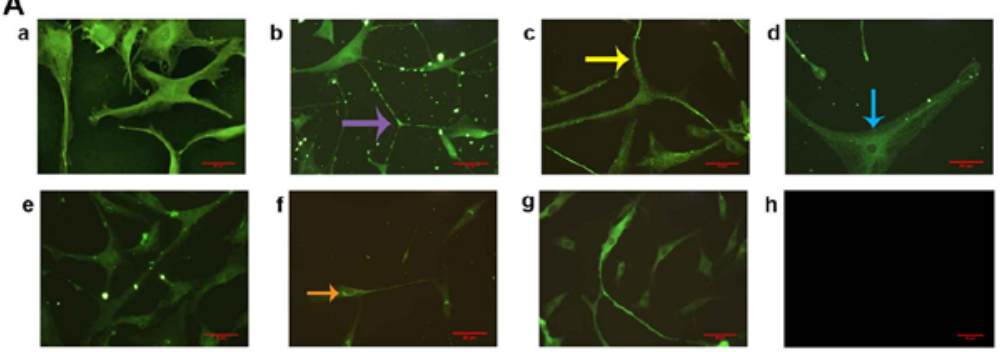

B
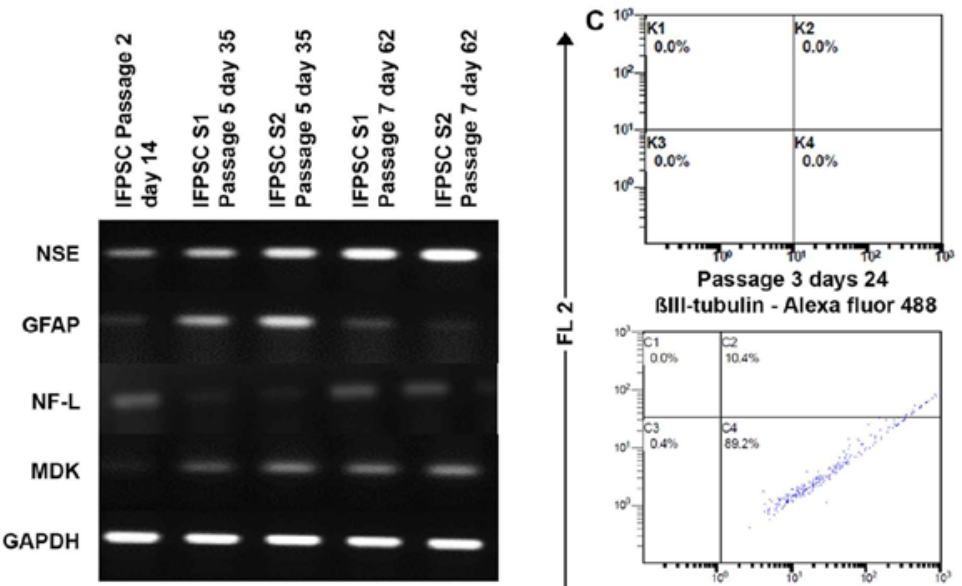

管

BIII-tubulin - Alexa fluor 48

만

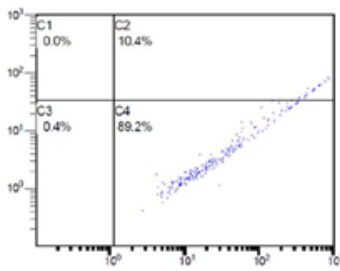

Passage 6 days 42

BIII-tubulin - Alexa fluor 488

$\mathrm{D}_{\mathrm{a}}$

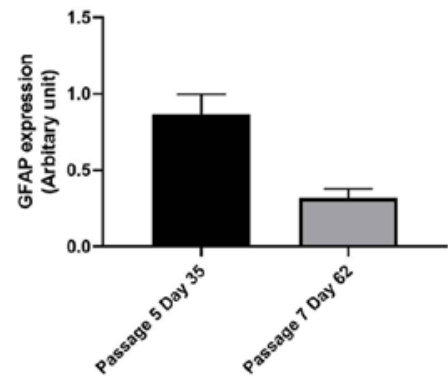

b

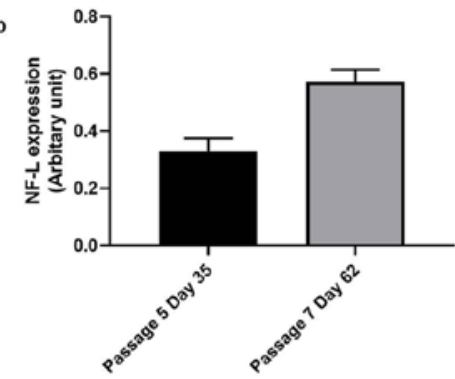

d

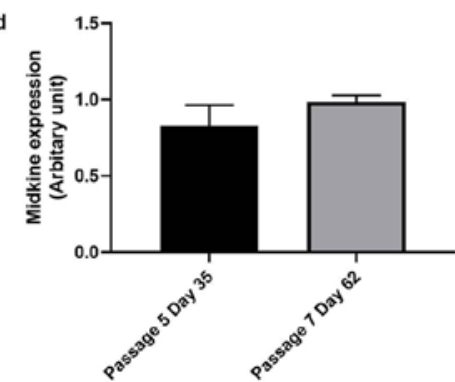

Figure 5. (A) Immunocytochemical analysis of IFPSCs on day 42 (>P6) indicated positivity for all the neuronal markers tested (magnification, x20), as follows: (a) NSE; (b) GAP43, with the purple arrow indicating that axons are concentrated with GAP43; (c) NF-L, with the yellow arrow indicating discrete points of NF-L positivity in the filament and cytoplasm; (d) SNAP25, with the blue arrow showing its concentration in the center and distribution along the axonal projections; (e) Olig2, with more uniform distribution observed across the cell compared with the localized expression of other proteins, where there is a clear delineation of the nucleus; (f) syntabulin, with the orange arrow showings its Golgi localization and distribution in a thin line along the axonal projections; (g) MAP2; and (h) negative control. Scale bar, $50 \mu \mathrm{m}$. (B) Semi-quantitative gene expression profile of neuronal markers in the protracted culture of IFPSCs at P5, day 35 and P7 day 62. IFPSCs from P2 (day 14) served as the control. (C) Flow cytometric comparative analysis of fluorescent protein expression in IFPSCs from P3 and P6. Expression of neuron-specific marker $\beta$-tubulin III was expressed at P6 (89.2\%), whereas it was absent at P3. (D) Semi-quantification of reverse transcription-polymerase chain reaction was conducted using ImageJ software and results were normalized to GAPDH. (a) GFAP, (b) NF-L, (c) NSE and (d) MDK expression was analyzed. Statistical analysis was conducted using Student's t-test. There was an increase in the expression of neuronal specific makers NSE, NF-L and MDK at P7 day 62 IFPSCs, infrapatellar fat pad-derived stem cells; NSE, neuron-specific enolase; GAP43, growth-associated protein 43; MDK, midkine; NF-L, neurofilament-L; SNAP25, synaptosomal-associated protein 25; Olig2, oligodendrocyte transcription factor 2; MAP2, microtubule-associated protein 2.

Syntabulin, a Golgi-localized protein involved in the anterograde axonal transport, was present in the perinuclear region and protracted along the neuronal processes. Furthermore, the presynaptic fusion protein SNAP25 was concentrated in the perinuclear region and distributed sparsely along the neuronal filaments. NF-L, which is involved in transport, was 


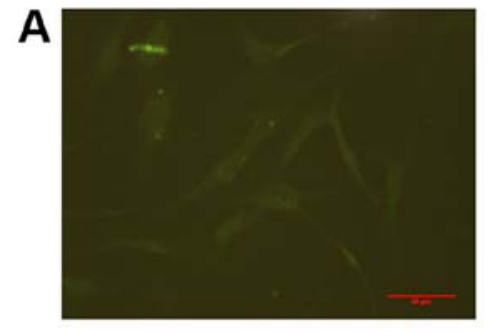

Passage 3 day 21 NSE

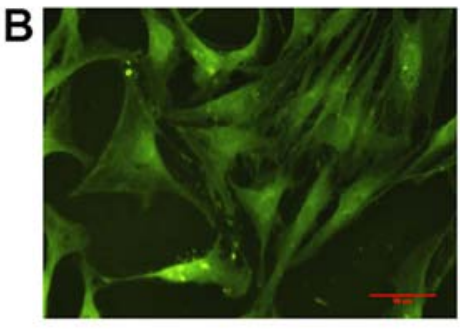

Passage 5 day 35 NSE

Figure 6. Immunocytochemical analysis of infrapatellar fat pad-derived stem cells for pan-neural marker NSE at (A) early P3 (day 21) and (B) late P5 (day 35). NSE was not detected in P1-P4, and its expression began only in P5 (day 35). Magnification, x20; scale bar, $50 \mu \mathrm{m}$. NSE, neuron-specific enolase.

widely expressed all over the cells and appeared in the form of discrete pockets of expression. Expression of MAP2, which is associated with dendrite elongation, was also detected in the cells. Finally, Olig2, a transcription factor involved in ventral neuroectodermal progenitor cell fate, was also expressed in the differentiating cells (Fig. 5A).

As shown in Fig. 5B, semi-quantitative gene expression analysis revealed the stage-specific expression of GFAP and NF-L in the early and late passages, respectively (17-20). As these intermediate filaments are cell-type specific, early neural stem/precursor cells exhibited high GFAP expression at P5, whereas its expression was reduced at P7; however, at P5, cells exhibited low NF-L expression, whereas upon neuronal differentiation these cells exhibited higher NF-L expression levels at passage P7 (Fig. 5Da and b). NSE, which has neurotrophic and neuroprotective properties, was sparsely expressed in the early passages and strongly expressed in later passages (Fig. 5Dc). Similarly the neurite outgrowth-promoting factor MDK was not expressed in cells at day 14 (P2), but was expressed by P5 and 7 (Fig. 5Dd). In addition, as shown in Fig. 5C, the expression of neural-specific marker $\beta$-tubulin III was considerably increased at P6, despite this being absent at P3. Parallel immunostaining also revealed that NSE was localized in the cytoplasm of IFPSCs from P5, whereas faint expression of NSE was observed earlier, at day 21 (P3; Fig. 6); however, the cells were negative for expression of other neuron-specific markers. Taken together, these results indicated that IFPSCs spontaneously acquire expression of neuronal markers at later passages and become neural lineage cells.

Loss of NS in the nuclear compartment and reduction in the expression of NSduring prolonged culture of IFPSC s maypredict loss of stemness. At day 14 (P2), NS was localized predominantly in the nucleolus, and was expressed in the nucleoplasm at day $28(\mathrm{P} 4)$. As the cells spontaneously progressed toward neuronal differentiation, the cellular localization of NS disappeared from the nucleus and was completely lost at later stages (Fig. 7A). No changes in the localization pattern of CD166 and CD105 were observed between days 0 and 28. As a reduction in cell number was observed at later passages, the expression of NS was analyzed in the IFPSCs from all three samples on days 14, 28 and 42, with GAPDH serving as the endogenous control. This analysis revealed a slight reduction in NS expression at day 42 (Fig. 7B and C).
Early IFPSCs (P2 day 14) express high levels of NS and have the ability to differentiate into all three germ layers Differentiation into the neuroectodermal lineage. IFPSCs at day 14 (P2) of culture were differentiated into neural lineage cells when cultured in DMEM serum-free media supplemented with bFGF, an established neural inducer. Once the neural induction media were added, the cells became elongated with numerous neurite outgrowths formed. Reduced cell proliferation was observed as the differentiation progressed further. At day 18 after induction, the cells were immunostained with the neural-specific marker MAP2, confirming neurogenic differentiation. Additionally, the gene expression analysis revealed that bFGF-induced cells expressed the neuron-specific proteins NSE, NF-L and MDK, with a gradual increase in the expression levels of NSE and NF-L detected by western blot analysis (Fig. 8A-C).

Differentiation into hepatocyte lineage. Cells at day 14 (P2) of culture were supplemented with the pre-induction medium, followed by hepatic induction and hepatic maturation media. During hepatic transdifferentiation, the IFPSCs retained their spindle shape during preconditioning, whereas exposure to the induction medium resulted in the cells becoming flat and broad. Later, during the maturation phase, the cells acquired the classical cuboidal to polygonal shape of hepatocytes. Unlike for the other two lineages, the endoderm lineage differentiation occurred much more slowly. At day 28 after induction, the cells were positive for the definitive endoderm marker Sox 17, confirming the lineage specificity. Functional hepatocyte-specific markers were expressed in differentiated hepatocytes, including TAT, albumin and TO. When TAT and albumin were constitutively expressed, there was a reduction in the expression of TO, which indicated stringent maintenance of differentiated hepatocytes in vitro (Fig. 8D-F).

Differentiation into osteogenic lineage. When day 14 (P2) IFPSCs were cultured in osteogenic induction media, they differentiated into osteogenic lineage cells and exhibited mineralization. Compared with the IFPSCs, the proliferation of adipose tissue-derived osteogenic cells (ADOCs) was considerably higher. Cells formed reticular structures, rather than the classical spindle-shaped stem cells. Osteogenic differentiation at day 18 after induction was confirmed by immunostaining with collagen I antibody. The differentiated 
$\underset{\mathrm{a}}{\mathrm{A}}$

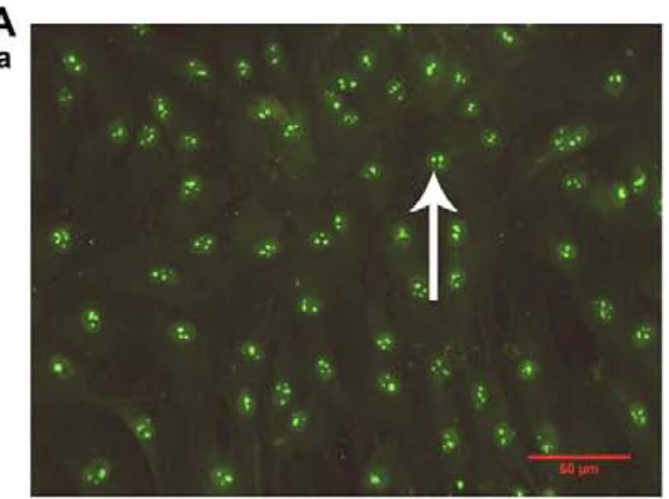

Passage 2 day 14

C

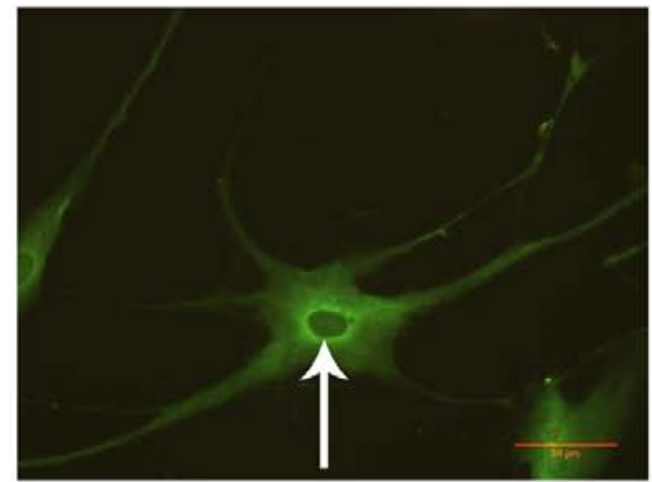

Passage 6 day 42

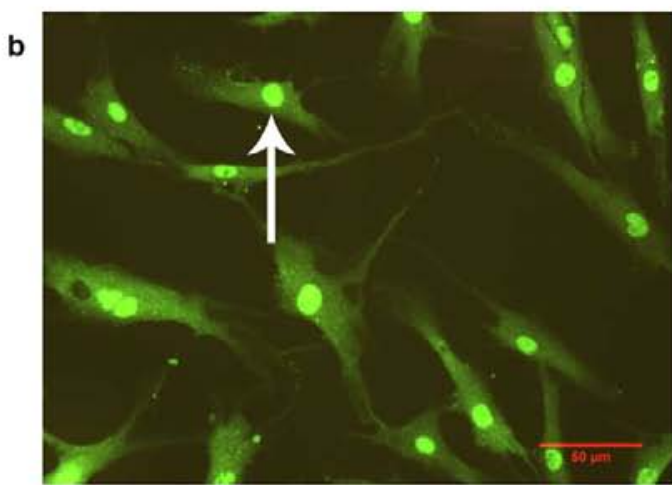

Passage 4 day 28

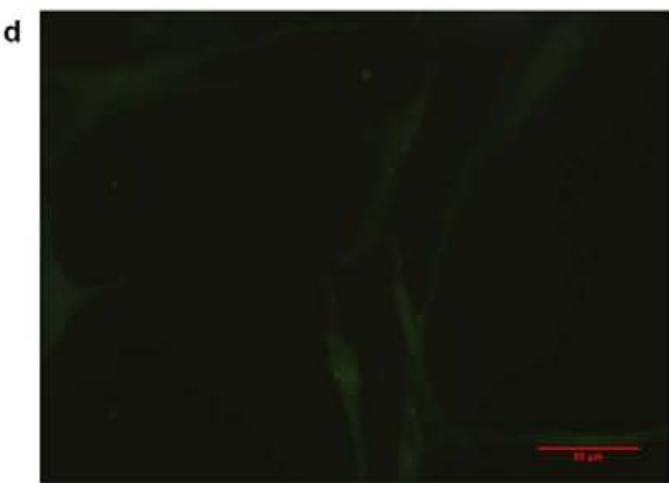

Passage 7 day 80

B

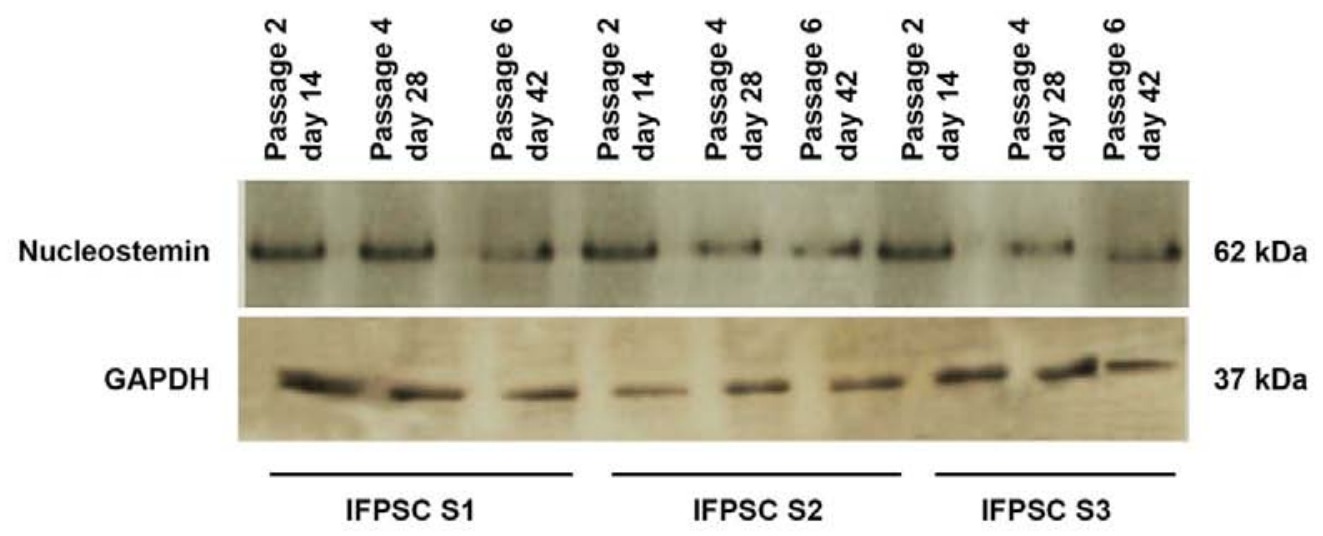

C

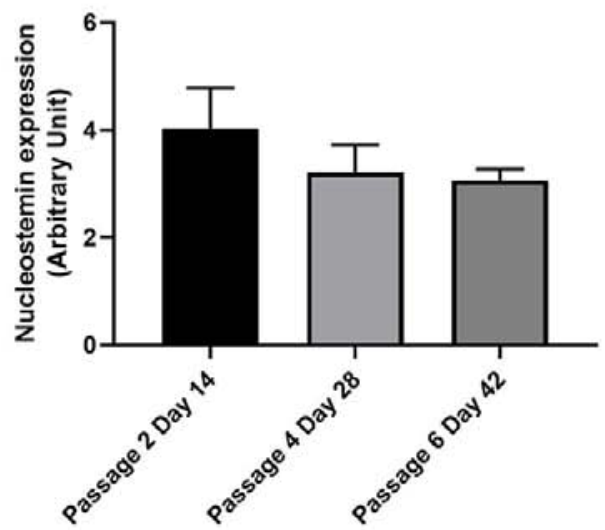

Figure 7. (A) Immunocytochemical images showing the localization of NS at a specific cellular compartment in infrapatellar fat pad-derived stem cells between P2 and P6 (magnification, x20), as follows: (a) NS is present only in the nucleolus at P2 (day 14), as indicated by the arrow; (b) NS expression is extended to the nucleoplasm at P4 (day 28), as indicated by the arrow; (c) at P6 (day 42), NS in the nucleus disappeared (arrow); (d) complete loss of NS was exhibited at P7 (day 80). Scale bar, $50 \mu \mathrm{m}$. (B) Reduction in the expression of the stem cell proliferative marker NS from P2 (day 14) to P6 (day 42) was demonstrated by western blot analysis $(n=3)$. (C) Semi=-quantification of band intensity was conducted using ImageJ software and results were normalized to GAPDH. Statistical analysis of the quantification was conducted using one-way analysis of variance with post-hoc Tukey test. NS, nucleostemin. 
A

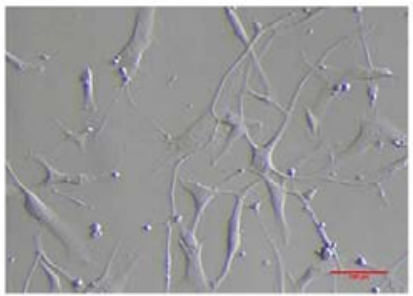

D

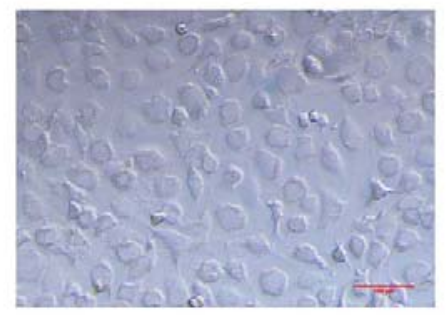

G

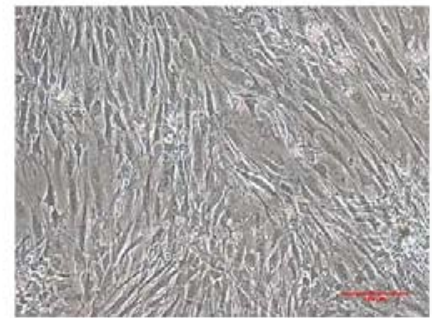

B

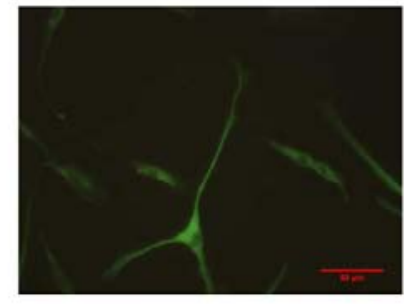

E

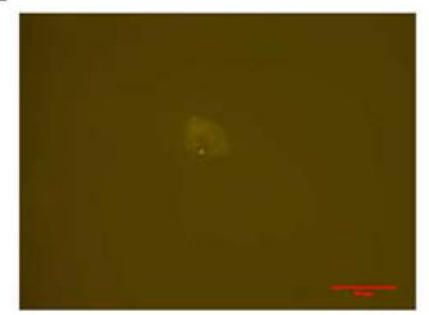

H

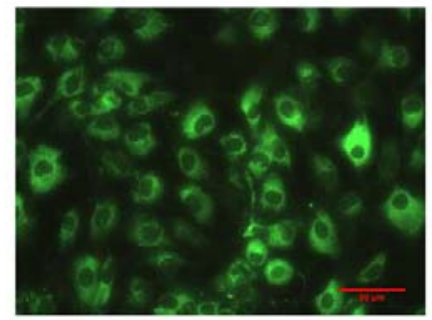

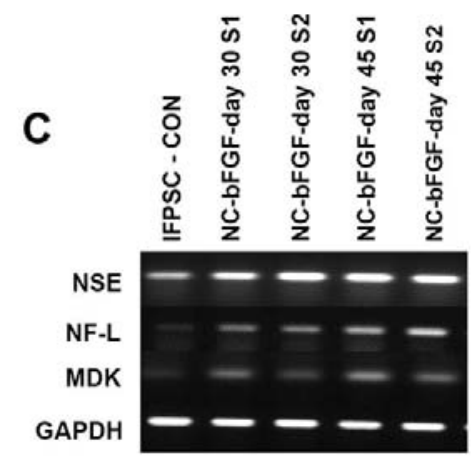
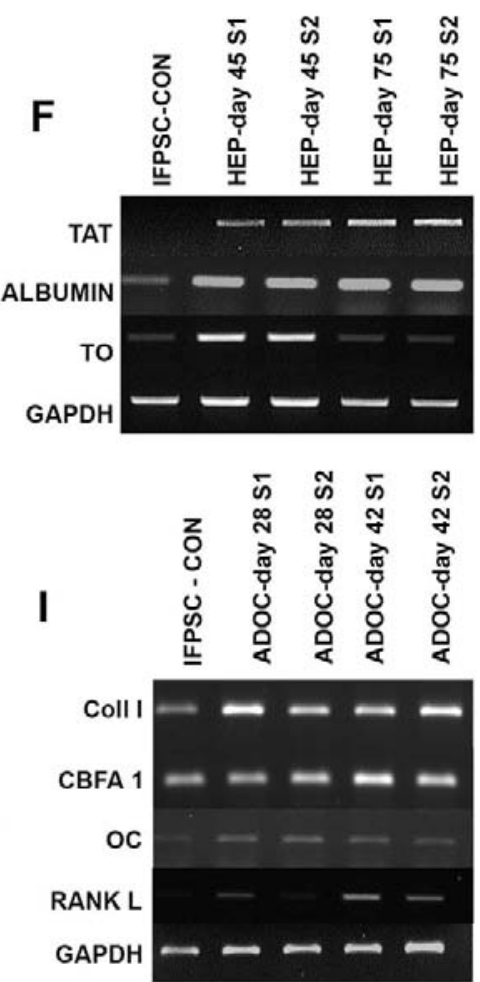

Figure 8. Differentiation of nucleostemin-expressed cells (early P2 day 14) to all three germ layers proved their stemness. Morphological analysis (magnification, x10; scale bar, $100 \mu \mathrm{m}$ ) validated the cell differentiation, immunocytochemical analysis (magnification, x20; scale bar, $50 \mu \mathrm{m}$ ) indicated the cell specificity, and semi-quantitative gene analysis validated their functionality. (A) Morphological analysis of neuroectoderm neuronal lineage cells, (B) immunocytochemical analysis of neuronal marker MAP2 at day 18 after neural induction, and (C) neural-specific gene expression. (D) Morphological analysis of definitive endoderm hepatocytes, (E) immunocytochemical analysis of their marker Sox17 at day 28 after induction, and (F) hepatocyte-specific gene expression. (G) Morphological analysis of mesoderm osteogenic cells, (H) immunocytochemical analysis of the marker collagen I at day 18 after induction, and (I) osteogenic gene expression. S1 and S2 represent samples 1 and 2, respectively. MAP2, microtubule-associated protein 2; Sox17, SRY-box 17.

cells synthesized the collagen fibers required to create the extracellular matrix for bone tissue. Furthermore, the gene expression analysis revealed that the ADOCs expressed CBFA1, which is an essential transcription factor involved in osteogenic differentiation. ADOCs also expressed osteocalcin, a non-collagenous bone hormone, and RANKL, which regulates osteogenic differentiation (Fig. 8G-I).

Taken together, these results confirmed the generation of three specific germ layers from NS-rich day 14 (P2) cells that was induced by specific culture conditions.

Immunophenotypic characterization of IFPSCs using flow cytometric analysis. The expression of stem cell markers CD90 and CD166 was considerably reduced in P3 IFPSCs compared with that in P2 IFPSCs. By contrast, nestin, an intermediary filament protein expressed in early neuronal cells, was absent in P1 and P2 cells; however, nestin was expressed in P3 IFPSCs (Fig. 9A-C). This indicated that passaging has an impact on the stemness of IFPSCs, as the cells moved toward a more specialized cell phenotype.

IFPSCs secrete neurotrophic factors and express neurotrophic receptors. The FTIR spectrum produced from analysis of the collected conditioned medium is presented in Fig. 10A. Three prominent peaks were observed at 1,218, 1,641 and 3,334 $\mathrm{cm}^{-1}$ in the conditioned medium obtained from all samples. The peak at $1,218 \mathrm{~cm}^{-1}$ reflects the $\mathrm{C}-\mathrm{N}$ and $\mathrm{N}-\mathrm{H}$ bending of secondary structures of proteins (21), whereas the peak at $1,641 \mathrm{~cm}^{-1}$ corresponds to the $\beta$-sheet of secondary structures that is present in nerve growth factors, including brain-derived 

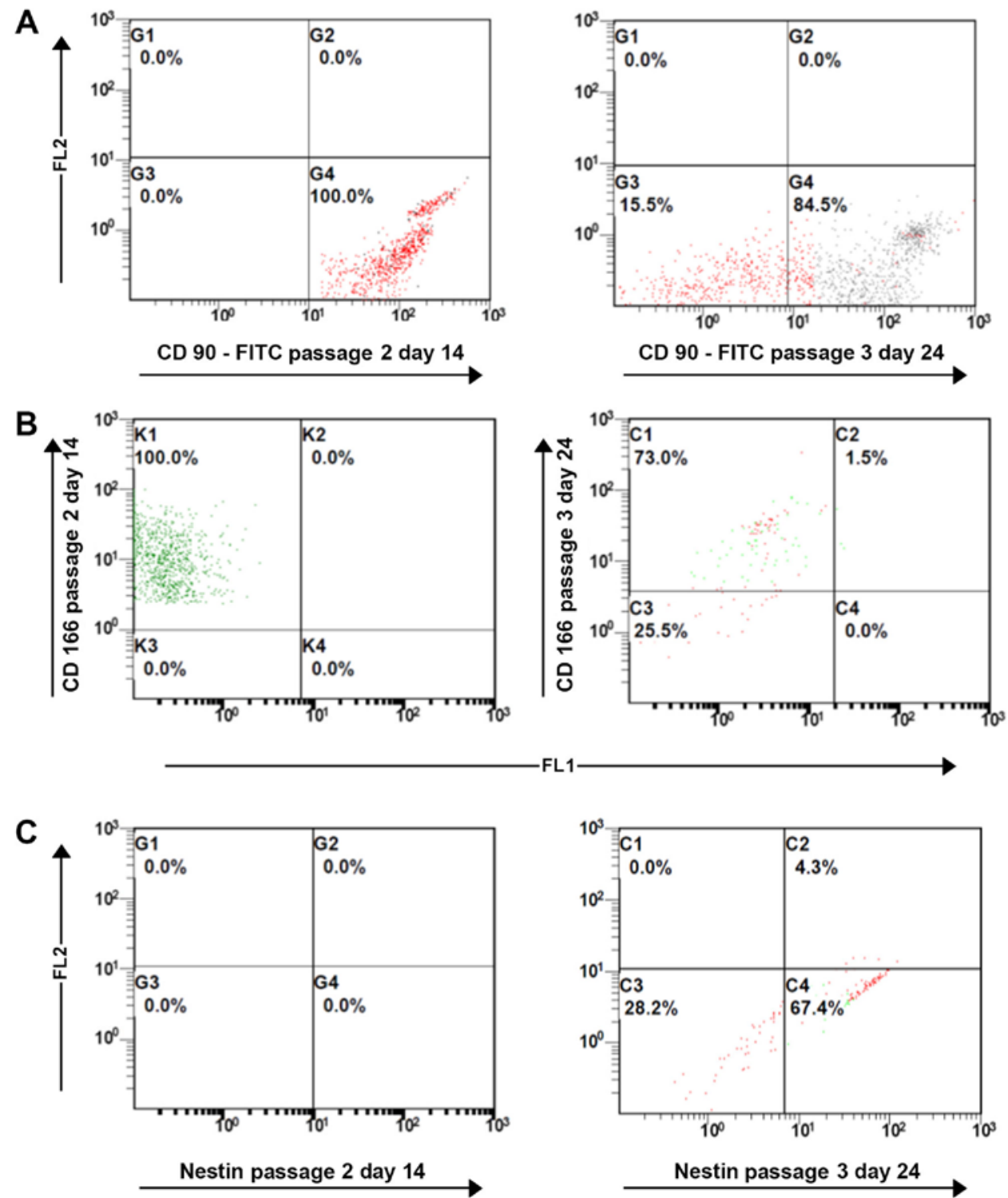

Figure 9. Flow cytometric comparative analysis of fluorescent protein expression in infrapatellar fat pad-derived stem cells from P2 and P3. Expression of (A) CD90 and (B) CD166, two mesenchymal stem cell markers, at P3 showed a 15.5 and 27\% reduction, respectively. (C) Expression of nestin, an early neuronal marker from P3, showed a steep increase (67.4\%) compared with P2.

neurotrophic factor, neurotrophin 3 , and nerve growth factor (NGF) $(22,23)$. The $3,334 \mathrm{~cm}^{-1}$ peak in the conditioned medium spectrum corresponds to the amide bond and $\mathrm{C}=\mathrm{C}-\mathrm{H}$ asymmetric stretch of the aromatic rings of phenylalanine $(22,23)$ that is present in neurotrophic factors. These results confirmed the presence of neurotrophic growth factors in the conditioned medium.

Expression of NTRK1 in early passages of IFPSCs. It is well established that neurotrophic factors exert their function by binding to the neurotrophic tyrosine kinase receptor NTRK1/TrkA $(24,25)$. Thus, the present study investigated whether IFPSCs at early passages express NTRK1 and whether this expression may lead to the progression of IFPSCs toward neuronal differentiation spontaneously. As shown in Fig. 10B, the results of the present study confirmed the expression of NTRK1 on IFPSCs at day 14 (P2), day 28 (P4) and day 35 (P5). Taken together, neurotrophic factors secreted by the IFPSCs may bind to the receptor in an autocrine/paracrine manner, which may induce cell signaling and drive IFPSCs towards neuronal differentiation.

\section{Discussion}

The present study investigated whether IFP tissue is a good source of autologous stem cells. IFP can be collected as medical waste during knee arthroplasty or harvested using simple arthroscopic techniques (26). The yield of MSCs obtained from IFP is significantly higher than that of bone marrow-derived stem cells (BMSCs) and subcutaneous adipose tissue $(4,11)$. In this study, it was demonstrated that IFPSCs possess a good proliferation capacity. The mean time of culture required for IFPSCs to reach P2 from P0 ranged at 12.25 2.5 days. In addition, it was confirmed that IFPSCs were clonogenic and expressed ADSC surface markers. IFPSCs at P2 were enriched in stemness characteristics and had differentiation 

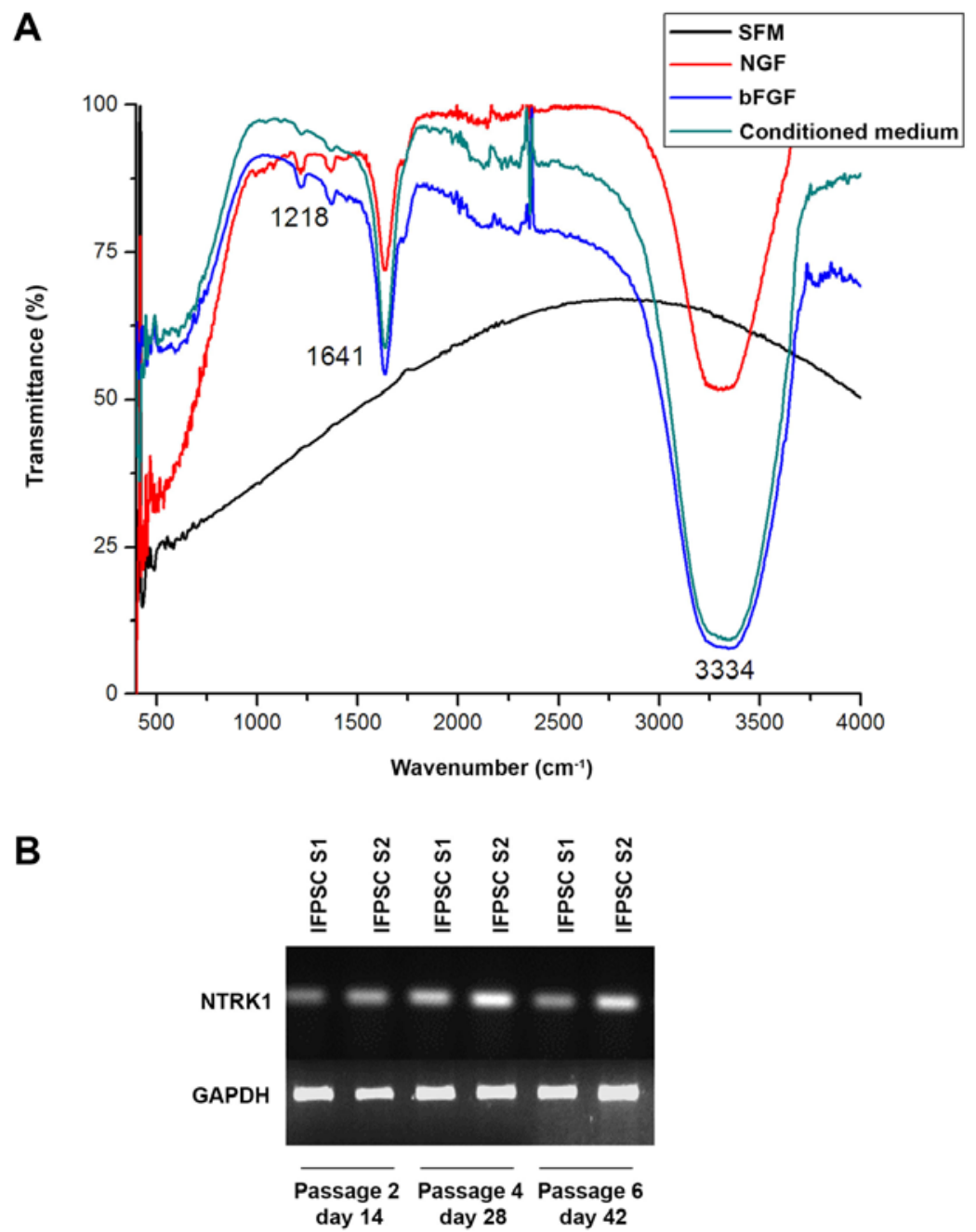

Figure 10. (A) Fourier transform infrared spectra of neurotrophic factors NGF, bFGF and conditioned medium from P2 IFSCs. The spectra showed three characteristic peaks corresponding to the specific functional groups in the secondary structures of the proteins. SFM was used as the negative control. (B) Semi-quantitative gene expression analysis of NTRK1 gene in infrapatellar fat pad-derived stem cells from P2 (day 14) to P6 (day 42) (n=2). GAPDH served as the endogenous control. NFG, nerve growth factor; bFGF, basic fibroblast growth factor; NRTK1, neurotrophic receptor tyrosine kinase 1; SFM, serum-free medium.

potential, expressing MSC and ESC markers. Taken together, IFPSCs should be considered as a suitable candidate cells for use in autologous cell-based therapies; however, obtaining clinical-grade stem cells in large numbers without the loss of phenotype and stemness remains a great challenge for tissue engineering and stem cell-based therapies.

The present study demonstrated that, during prolonged in vitro expansion of IFPSCs, the number of passages had a significant impact on the stemness, indicated by differential expression of the proliferative marker NS at the subcellular level. A previous study by Ali et al (27) supported the use of NS-based predictive indication of proliferation and reported the importance of NS in subgrouping HSCs from the aspirates of bone marrow. HSCs with high NS expression have been proven to have specific stem cell signatures and characteristics. NS, in general, regulates the proliferation rate of stem/progenitor cells in vivo via p53-dependent and p53-independent mechanisms (28). In the current study, a stage-wise change in the intensity and cellular localization of NS over P2 (predominantly in the nucleolus), P4 (in the nucleoplasm), P5 (diminished in the nucleoplasm) and P6-7 (completely absent in the nucleus) was observed. In addition to its nucleolar and nucleoplasm localization in interphase cells, the presence of NS at chromosome arms during mitosis was observed. The presence of NS in the cytoplasm at later passages may be due to the disruption of microtubule-induced dissociation of NS from the chromosome arms at interphase (29). The present study also observed that at P7 (>day 80), NS was completely absent from the differentiated cells. In a spatiotemporal expression study of NS in stem cells derived from umbilical cord and deciduous dental pulp samples, Oktar et al (29) demonstrated that NS is a proliferation marker that directly reflects in vitro expansion capabilities, which is downregulated following induced adipogenic differentiation. Additionally, marked downregulation of NS occurs prior to terminal differentiation (30-32). The marked decrease in NS results in prolonged G1 phase or G1 arrest in cells, with activation of mitogen-activated protein kinase kinase/extracellular signal-regulated kinase signaling for stem/progenitor cells to acquire the gene expression and morphological differentiation (32). A schematic representation of the postulated mechanism associated with the expression of NS is presented in Fig. 11 (32-34). Thus, in the present study, the downregulation of NS after P5, prior to spontaneous differentiation of IFPSCs, indicates the loss of stemness. The 

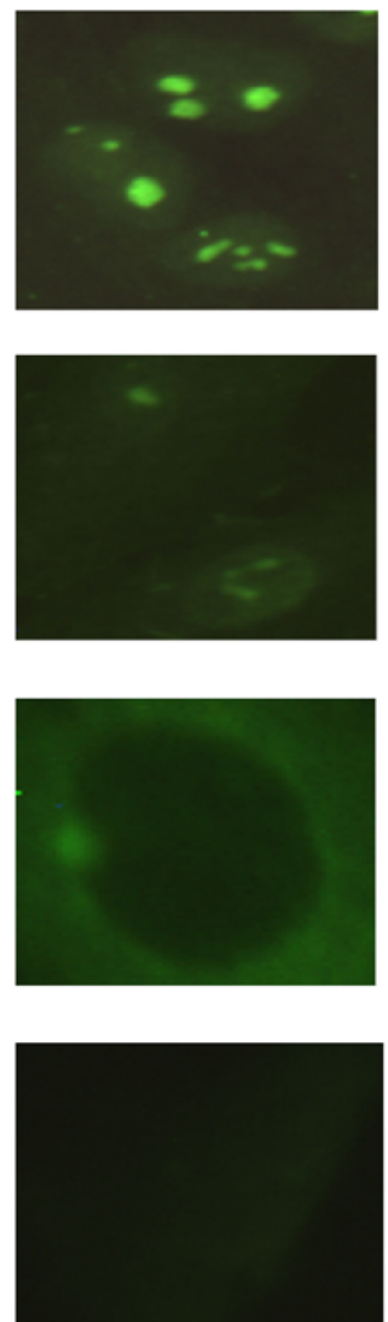

IFPSCs

(NS Shuttles between

nucleolus and nucleoplasm)

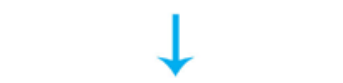

Brevity of G1 phase in cell cycle shown enhanced proliferation

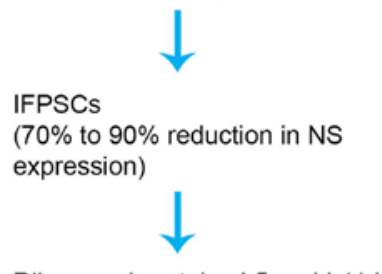

Ribosomal proteins L5 and L11 bind to MDM2 and inhibit P53 repression

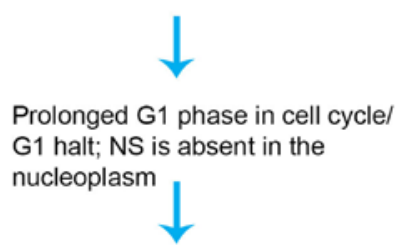

MEKJERK protein kinases become active due to protracted $\mathrm{G} 1$

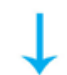

Changes in gene expression and morphological differentiation

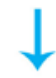

Complete loss of NS at Passage 7 day 80

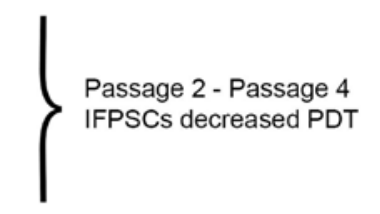

Passage 5 -

Passage 6 IFPSCs increased PDT

Figure 11. Postulated mechanism of NS and its correlation with stemness in IFPSCs. NS, nucleostemin; IFPSCs, infrapatellar fat pad-derived stem cells; PDT, population doubling time.

role of NS expression in conferring and identifying stemness in IFPSCs also requires further investigation in vivo.

Morphological assessment in the current study further revealed that IFPSCs at later passages (>P5) lost their fibroblastic structure that is characteristic in early passages (P2-P4). At later passages, cells were long and thin, with two or more nerve fibers resembling dendrite and axonal outgrowths of neurons. In our previous study, a subset of IFPSCs was found to differentiate into neuronal lineage cells without any specific induction (6); thus, in the present study, the cells were analyzed for early neuronal markers at each passage. A steep increase in the expression of nestin was observed at P3. In later passages, in order to rule out that cell-cell outgrowths were filopodia, specific immunostaining was performed with antibodies specific to GAP43, a protein involved in axonal growth, and MAP2, which is involved in dendrite elongation. Along with these markers, IFPSCs at later passages expressed an array of neural-lineage specific markers, including NSE, SNAP25, syntabulin and NF-L (Fig. 5).

A technical limitation of the present study is the use of fluorescence microscopy without multiple filters, which could not support co-localization studies. As discussed earlier, the study was performed without using an external induction stimulus, except for the differentiation of the three germ layers. Thus, it is apparent that IFPSCs have the intrinsic ability to secrete inducible neurogenic factors. Additionally, medium from $\mathrm{P} 2$ cells (serum-free conditioned medium) was examined using FTIR spectrometry. The results revealed peaks at 1,218,1,641 and $3,334 \mathrm{~cm}^{-1}$, which corresponded to protein secondary structures that are characteristic of the neurotrophic factors NGF and bFGF $(22,23,35,36)$, as well as demonstrated the ability of IFPSCs to secrete known neural inducers. Previous studies have established the role of bFGF in cell proliferation through the autocrine and paracrine signaling mechanisms (37-42). Another study indicated that bFGF can only induce neuronal differentiation of BMSCs in vitro (43). The present study further confirmed that IFPSCs express NTRK1, which is a receptor for NGF. These findings indicated that IFPSCs are able to secrete neurotrophic factors for autocrine/paracrine signaling, leading to differentiation of IFPSCs into neurons at later passages. Furthermore, the spontaneous neural induction was also demonstrated quantitatively with $\beta$-tubulin III protein expression in IFPSCs from P6. The current study, thus, suggests that IFPSCs are an ideal candidate for use in neurological cell-based therapies. 
A change was identified in the characteristics of IFPSCs when cultured for long durations compared with early passage cells. The changes included increased PDT with an increase in passage number. Cells at passages $>5$ exhibited a longer PDT and reduced proliferative ability. Multiple studies have reported the association between the increase in mean doubling time and the increase in the passage number of MSCs $(44,45)$. The IFPSCs used in the current study were isolated from medical waste obtained during knee arthroplasty that was performed on aged patients with arthritis. Despite the samples being from aged patients with arthritis, the IFPSCs obtained were rich in stemness markers and demonstrated a capacity for three germ layer differentiation. Therefore, rejuvenation of cultured IFPSCs may reverse the impaired proliferative ability and loss of stemness at later passages. Culturing the cells in hypoxic conditions or with sera obtained from younger individuals would provide a microenvironment that is more similar to the physiological conditions $(46,47)$. The use of 5-azacytidine, an epigenetic modulator, has been reported to reduce the global methylation level in stem cells obtained from aged donors $(45,48)$. Future studies should focus on large-scale production of clinical grade IFPSCs, using rejuvenating factors to prolong their stemness.

Finally, Wu et al (49) have supported the use of MSCs for therapeutic purposes; however, the number of passages used should be selected with the utmost care when designing cell-based therapeutic strategies. In a clinical study of acute graft versus host disease, patients were treated with MSCs from P1-4 (50). The MSCs from P1 and P2 exhibited improved responses and a higher survival rate $(71 \%)$ in patients; by contrast, patients treated with P3 and P4 MSCs had a lower survival rate (21\%), although the cells exhibited no morphological and functional differences in vitro (50). Furthermore, Moll et al (51) reported that there was an increased instant blood-mediated inflammatory reaction following systemic infusion of MSCs that had been expanded for a prolonged duration ex vivo, which is highly deleterious. The functionality of these therapeutic cells can be retained using low-passage clinical grade MSCs. The findings of the present study further suggest that reduced clinical efficacy may be due to the loss of stemness with the increasing number of passages.

In conclusion, in the current study, early passage IFPSCs (P2 and P3) were identified to be MSCs with various stem cell characteristics. Prolonged culture of IFPSCs led to the loss of the proliferative marker NS in the nucleolus and the nucleoplasm, along with the development of a neurogenic phenotype. The intensity and subcellular localization of NS may be useful as a dynamic marker for stemness. Finally, well-characterized IFPSCs from early passages (P2-4) may be useful in differentiation protocols and cell-based therapies.

\section{Acknowledgements}

Not applicable.

\section{Funding}

The present study was funded by the Department of Science and Technology, Ministry of Science and Technology, Government of India (grant no. SR/WOS-A/LS-193/2012).

\section{Availability of data and materials}

All data generated or analyzed during the present study are included in this published article.

\section{Authors' contributions}

SR and OAT participated in the conception and design of the study. SR and CAM performed the experiments. SR, MSR and SS collected and analyzed the data. SR, CAM and MC performed the flow cytometric analysis and biophysical characterization. NK designed and analyzed the biophysical characterization experiments. SR wrote the manuscript. MR supervised the study and gave final approval of the study, and was also involved in analyzing and interpreting the data. MR and SS critically reviewed and edited the article. All the authors have read and approved the final version of this manuscript.

\section{Ethics approval and consent to participate}

The Ethical Committee of MIOT Institute of Research (IEC/MIR/0003/14) and National Foundation for Liver Research (HR/2016/MS/004) approved the study, and the Institutional Committee for stem cell research of these two centers approved the respective protocol. Informed consent was obtained from all the participants.

\section{Patient consent for publication}

All patients provided written informed consent for the publication of data in this study.

\section{Competing interests}

The authors declare that they have no competing interests.

\section{References}

1. Zuk PA, Zhu M, Mizuno H, Huang J, Futrell WJ, Katz AJ, Benhaim P, Lorenz HP and Hedrick MH: Multilineage cells from human adipose tissue: Implications for cell-based therapies. Tissue Eng 7: 211-226, 2001.

2. Zuk PA: The adipose-derived stem cell: Looking back and looking ahead. Mol Biol Cell 21: 1783-1787, 2010.

3. Davies DV and White JE: The structure and weight of synovial fat pads. J Anat 95: 30-37, 1961.

4. Dragoo JL and Chang W: Arthroscopic harvest of adipose-derived mesenchymal stem cells from the infrapatellar fat pad. Am J Sports Med 45: 3119-3127, 2017.

5. Arumugam SB, Trentz OA, Arikketh D, Senthinathan V, De Rosario B and Mohandas PV: Detection of embryonic stem cell markers in adult human adipose tissue-derived stem cells. Indian J Pathol Microbiol 54: 501-508, 2011.

6. Radhakrishnan S, Trentz OA, Parthasarathy VK and Sellathamby S: Human adipose tissue-derived stem cells differentiate to neuronal-like lineage cells without specific induction. Cell Biol (Henderson, NV) 6, 2017.

7. Trentz OA, Arikketh D, Sentilnathan V, Hemmi S, Handschin AE, de Rosario B, Mohandas P and Mohandas PV: Surface proteins and osteoblast markers: Characterization of human adipose tissue-derived osteogenic cells. Eur J Trauma Emerg Surg 36: 457-463, 2010.

8. Turinetto V, Vitale E and Giachino C: Senescence in human mesenchymal stem cells: Functional changes and implications in stem cell-based therapy. Int J Mol Sci 17: pii: E1164, 2016.

9. Wall ME, Bernacki SH and Loboa EG: Effects of serial passaging on the adipogenic and osteogenic differentiation potential of adipose-derived human mesenchymal stem cells. Tissue Engg 13: 1291-1298, 2007. 
10. Madeira A, da Silva CL, dos Santos F, Camafeita E, Cabral JM and Sá-Correia I: Human mesenchymal stem cell expression program upon extended ex-vivo cultivation, as revealed by 2-DE-based quantitative proteomics. PLoS One 7: e43523, 2012.

11. Tangchitphisut P, Srikaew N, Numhom S, Tangprasittipap S, Woratanarat P, Wongsak S, Kijkunasathian C, Hongeng S, Murray IR and Tawonsawatruk T: Infrapatellar fat pad: An alternative source of adipose-derived mesenchymal stem cells. Arthritis 2016: 4019873 , 2016.

12. Kim HJ, Ryu YH, Ahn JI, Park JK and Kim JC: Characterization of immortalized human corneal endothelial cell line using HPV 16 E6/E7 on lyophilized human amniotic membrane. Korean J Ophthalmol 20: 47-54, 2006.

13. Bishi DK, Mathapati S, Venugopal JR, Guhathakurta S, CherianKM,RamakrishnaaSand VermaRS:Trans-differentiation of human mesenchymal stem cells generate functional hepatospheres on poly(L-lactic acid)-co-poly( $\varepsilon$-caprolactone)/collagen nanofibrous scaffolds J Mater Chem B 1: 3972-3984, 2013.

14. Lendahl U,Zimmerman LB and McKay RD: CNS stem cells express a new class of intermediate filament protein. Cell 60: 585-595, 1990

15. Lenka N and Ramasamy SK: Neural induction from ES cells portrays default commitment but instructive maturation. PLoS One 2: e1349, 2007.

16. Gallo-Oller G, Ordoñezb R and Dotorc J: A new background subtraction method for Western blot densitometry band quantification through image analysis software. J Immunol Methods 457: $1-5,2008$

17. Shim JW, Park CH, Bae YC, Bae JY, Chung S, Chang MY, Koh HC, Lee HS, Hwang SJ, Lee KH, et al: Generation of functional dopamine neurons from neural precursor cells isolated from the subventricular zone and white matter of the adult rat brain using Nurrl overexpression. Stem Cells 25: 1252-1262, 2007.

18. Casper KB and McCarthy KD: GFAP-positive progenitor cells produce neurons and oligodendrocytes throughout the CNS. Mol Cell Neurosci 31: 676-684, 2006.

19. Lariviere RC and Julien JP: Functions of intermediate filaments in neuronal development and disease. J Neurobiol 58: 131-48, 2004.

20. Liu Y, Namba T, Liu J, Suzuki R, Shioda S and Seki T: Glial fibrillary acidic protein-expressing neural progenitors give rise to immature neurons via early intermediate progenitors expressing both glial fibrillary acidic protein and neuronal markers in the adult hippocampus. Neuroscience 166: 241-25, 2010.

21. Kong $\mathbf{J}$ and $\mathrm{Yu} \mathrm{S}$ : Fourier transform infrared spectroscopic analysis of protein secondary structures. Acta Biochim Biophys Sin (Shanghai) 39: 549-559, 2007.

22. Narhi LO, Rosenfeld R, Talvenheimo J, Prestrelski SJ, Arakawa T, Lary JW, Kolvenbach CG, Hecht R, Boone T, Miller JA, et al: Comparison of the biophysical characteristics of human brain-derived neurotrophic factor, neurotrophin-3, and nerve growth factor. J Biol Chem 268: 13309-13317, 1993

23. Travaglia A, Satriano C, Giuffrida ML, Mendola DL, Rampazzo E, Prodid L and Rizzarelliab E: Electrostatically driven interaction of silica-supported lipid bilayer nano platforms and a nerve growth factor-mimicking peptide. Soft Matter 9: 4648-4654, 2013.

24. Segal RA: Selectivity in neurotrophin signaling: Theme and variations. Annu Rev Neurosci 26: 299-330, 2003.

25. Windisch JM, Marksteiner R and Schneider R: Nerve growth factor binding site on TrkA mapped to a single 24-amino acid leucine-rich motif. J Biol Chem 270: 28133-28138, 1995.

26. Doner GP and Noyes FR: Arthroscopic resection of fat pad lesions and infrapatellar contractures. Arthrosc Tech 3: e413-e416, 2014

27. Ali MAE, Fuse K, Tadokoro Y, Hoshii T, Ueno M, Kobayashi M, Nomura N, Vu HT, Peng H, Hegazy AM, et al: Functional dissection of hematopoietic stem cell populations with a stemness-monitoring system based on NS-GFP transgene expression. Sci Rep 7: 11442, 2017.

28. Beekman C, Nichane M, De Clercq S, Maetens M,Floss T, Wurst W, Bellefroid E and Marine JC: Evolutionarily conserved role of nucleostemin: Controlling proliferation of stem/progenitor cells during early vertebrate development. Mol Cell Biol 18: 9291-9301, 2006

29. Oktar PA, Yildirim S, Balci D and Can A: Continual expression throughout the cell cycle and downregulation upon adipogenic differentiation makes nucleostemin a vital human MSC proliferation marker. Stem Cell Rev 7: 413-424, 2011.

30. Tsai RY and McKay RD: A multistep, GTP-driven mechanism controlling the dynamic cycling of nucleostemin. J Cell Biol 168: 179-184, 2005.
31. Kafienah W, Mistry S, Williams C and Hollander AP Nucleostemin is a marker of proliferating stromal stem cells in adult human bone marrow. Stem Cells 24: 1113-1120, 2006.

32. Qu J and Bishop JM: Nucleostemin maintains self-renewal of embryonic stem cells and promotes reprogramming of somatic cells to pluripotency. J Cell Biol 197: 731-745, 2012

33. $\mathrm{Ma} \mathrm{H}$ and Pederson T: Nucleostemin: A multiplex regulator of cell-cycle progression. Trends Cell Biol 18: 575-579, 2008.

34. Lo D and Lu H: Nucleostemin: Another nucleolar 'Twister' of the p53-MDM2 loop. Cell Cycle 9: 16, 3227-3232, 2010.

35. Zaragosi LE, Ailhaud G and Dani C: Autocrine fibroblast growth factor 2 signaling is critical for self-renewal of human multipotent adipose-derived stem cells. Stem Cells 24: 2412-2419, 2006.

36. Rider DA, Dombrowski C, Sawyer AA, Ng GH, Leong D, Hutmacher DW, Nurcombe V and Cool SM: Autocrine fibroblast growth factor 2 increases the multipotentiality of human adipose-derived mesenchymal stem cells. Stem Cells 26: 1598-1608, 2008.

37. Chou $\mathrm{CH}$ and Modo M: Human neural stem cell-induced endothelial morphogenesis requires autocrine/paracrine and juxtacrine signalling. Sci Rep 6: 29029, 2016.

38. Cohen MA, Itsykson $\mathrm{P}$ and Reubinoff BE: The role of FGF-signaling in early neural specification of human embryonic stem cells. Dev Biol 340: 450-458, 2010.

39. Frautschya SA, Gonzaleza AM, Martinez Murillo R, Carcellerb F, Cuevasb P and Bairda A: Expression of basic fibroblast growth factor and its receptor in the rat subfornical organ. Neuroendocrinology 54: 55-61, 1991.

40. Gensburger C, Labourdette G and Sensenbrenner M: Brain basic fibroblast growth factor stimulates the proliferation of rat neuronal precursor cells in vitro. FEBS Lett 217: 1-5, 1987.

41. Gnecchi M, Zhang Z, Ni A and Dzau VJ: Paracrine mechanisms in adult stem cell signaling and therapy. Circ Res 103: 1204-1219, 2008.

42. Ying QL, Stavridis M, Griffiths D, Li M and Smith A: Conversion of embryonic stem cells into neuroectodermal precursors in adherent monoculture. Nat Biotechnol 21: 183-186, 2003.

43. Yang H, Xia Y, Lu SQ, Soong TW and Feng ZW: Basic fibroblast growth factor-induced neuronal differentiation of mouse bone marrow stromal cells requires FGFR-1, MAPK/ERK, and transcription factor AP-1. J Biol Chem 283: 5287-5295, 2008.

44. Gruber HE, Somayaji S, Riley F, Hoelscher GL, Norton HJ, Ingram $\mathbf{J}$ and Hanley EN Jr: Human adipose-derived mesenchymal stem cells: Serial passaging, doubling time and cell senescence. Biotech Histochem 87: 303-311, 2012.

45. Seeliger C, Culmes M, Schyschka L, Yan X, Damm G, Wang Z, Kleeff J, Thasler WE, Hengstler J, Stöckle U, et al: Decrease of global methylation improves significantly hepatic differentiation of Ad-MSCs: Possible future application for urea detoxification. Cell Transplant 22: 119-131, 2013.

46. Ahmed AS, Sheng MH, Wasnik S, Baylink DJ and Lau KW: Effect of ageing on stem cells. World J Exp Med 7: 1-10, 2017.

47. Ho AD, Wagner $\mathrm{W}$ and Mahlknecht U: Stem cells and aging. EMBO Rep 6 (Suppl 1): S35-S38, 2005

48. Yan X,EhnertS, Culmes M,Bachmann A, SeeligerC, SchyschkaL, Wang Z, Rahmanian-Schwarz A, Stöckle U, De Sousa PA, et al: 5-azacytidine improves the osteogenic differentiation potential of aged human adipose-derived mesenchymal stem cells by DNA demethylation. PLoS One 9: e90846, 2014.

49. Wu PK, Wang JY, Chen CF, Chao KY, Chang MC, Chen WM and Hung SC: Decreased radiosensitivity and increased DNA repair activity a demethylation. PLoS One 9: e90846.

50. von Bahr L, Sundberg B, Lönnies L, Sander B, Karbach H, Hägglund H, Ljungman P, Gustafsson B, Karlsson H, Le Blanc K and Ringdén O: Long-term complications, immunologic effects, and role of passage for outcome in mesenchymal stromal cell therapy. Biol Blood Marrow Transplant 18: 557-564, 2012.

51. Moll G, Rasmusson-Duprez I, von Bahr L, Connolly-Andersen AM, Elgue G, Funke L, Hamad OA, Lönnies H, Magnusson PU, Sanchez J, et al: Are therapeutic human mesenchymal stromal cells compatible with human blood? Stem Cells 30: 1565-1574, 2012.

This work is licensed under a Creative Commons Attribution-NonCommercial-NoDerivatives 4.0 International (CC BY-NC-ND 4.0) License. 